\title{
Types of social help-seeking strategies in different and across spe- cific task stages of a real, challenging long-term task and their role in academic achievement
}

\author{
Carmen Nadja Hirt ${ }^{\mathrm{a}}$, Yves Karlen ${ }^{\mathrm{a}}$, Francesca Suter ${ }^{\mathrm{b}}$, \& Katharina Maag Merki ${ }^{\mathrm{b}}$ \\ ${ }^{a}$ University of Applied Sciences and Arts Northwestern Switzerland, School of Education, Switzerland \\ ${ }^{\mathrm{b}}$ University of Zurich, Institute of Education, Switzerland
}

Article received 24 February 2020 / Article revised 9 June / Accepted 17 July / Available online 5 August

\begin{abstract}
Social help seeking (SHS) is an important strategy for successful self-regulated learning at all school levels. The aim of this longitudinal study is threefold: to ascertain the existence of different types of SHS strategies in various task stages of creating an individual academic paper, examine the extent to which these types of SHS strategies change in the course of that challenging long-term task and analyse the extent to which these types are relevant to academic achievement. This examination extends previous studies by adopting a task-specific, personcentred development perspective on SHS outside regular classroom instruction. In particular, we explore SHS types in the context of a real, long-term task, whereby aspects neglected in previous studies (need for help, help sources based on specific issue areas) are used for type creation and test for differences in academic achievement. Three online questionnaires were completed by 603 upper secondary school-level students $(62.9 \%$ female $)$ with a mean age of $17.3(S D=$ .71) within one school year. Latent class analyses, latent transition analyses (LTA) and nonparametric procedures (Kruskal-Wallis H test, post hoc DunnBonferroni test) were performed. Different SHS types were identified (independents, factual supervisor-focused, factual supervisor-focused and motivational family-focused, motivational family-focused, and factual and motivational family-focused) and found to vary over different task stages. Moreover, LTA indicated a considerable change between the SHS types over time. Nevertheless, no significant differences in achievement emerged between the types per task stage, thus reflecting the adage, 'There is more than one way of doing it'.
\end{abstract}

Keywords: Social help seeking, longitudinal study, latent class analyses, latent transition analyses, academic achievement 


\section{Introduction}

Learners usually encounter difficulties while working on a challenging task. One strategy for overcoming a difficulty that hinders further operations involves seeking help (Nelson-Le Gall, 1985; Newman, 2000). Help seeking (HS) is an important self-regulatory strategy (e.g. Newman, 2000; Pintrich \& Zusho, 2002) at all school levels (Järvelä, 2011), and it represents an important external resource management strategy for achieving goals (Schenke, Lam, Conley \& Karabenick, 2015). Some authors include seeking help from both personal and non-personal sources in their definition of HS (e.g. Aleven, Stahl, Schworm, Fischer \& Wallace, 2003); other authors such as Zimmerman and Moylan (2009) consider HS as "[...] a social form of information seeking" (p. 303). The social aspect of seeking help is emphasized in the latter, which distinguishes this strategy from information seeking (e.g. books, Internet and computer-supported, interactive learning environments). The HS strategy is used when a task cannot be completed on its own, which is also expressed by Nelson-Le Gall (1985) in her explanation of HS as an "adaptive alternative to individual problem solving" (p. 66). As the focus in the present study is on seeking help from other persons, information seeking from non-real personal supporters is excluded. The term social help seeking (SHS) is therefore used to underline this conceptual distinction. SHS differs from other self-regulation strategies (Schworm \& Fischer, 2006) because it requests interaction with other people such as teachers, peers and parents (Ellis, 1997; Karabenick \& Newman, 2010; Newman, 2000), thereby confirming its uniqueness, whereas technologically mediated HS can also be social if the presence of the other individual is real (e.g. phone call, e-mail) (Karabenick \& Newman, 2010). One consequence of the social-interactive character of the described form of help seeking is that it makes the SHS process vulnerable to a variety of influences (Karabenick \& Berger, 2013).

Most of the studies available on SHS aimed to determine whether help is sought, for what reasons and from whom and concluded that not every SHS is equally beneficial to learning (Wolters, Pintrich \& Karabenick, 2003). Making a distinction between the more and less productive forms of SHS is therefore important. Thus far, these forms of SHS have been primarily studied in the context of regular instruction, strongly based on the goals, reasons or orientations of the learners. This effort has resulted in the forms or types of instrumental SHS, executive SHS and SHS avoidance, with different effects on achievement, both in variable- and person-centred approaches. However, SHS does not only occur in the setting of regular instruction. School tasks for completion outside of regular instruction can also lead to difficulties and thus to SHS processes, where peers and teachers do not necessarily serve as source, but other people such as parents are possibly more likely to be available. Although the contextual resources can determine the rate and effectiveness of SHS (Karabenick \& Gonida, 2018), they have been hardly examined for educational tasks in the context beyond regular instruction.

The present study therefore seeks to examine SHS in an educational task outside the classroom environment, which consists in writing a compulsory school leaving certificate paper at the upper secondary school level. This paper is written individually or in groups outside of class during extracurricular time over approximately one year, and it entails three task stages (development, implementation and final stages). In this context, we aim to examine whether we can group SHS strategies into certain types at different stages during the entire process of developing the individual academic paper, through the adoption of a person-centred approach to focus on students as a complex system of interacting components. For the creation of these types, we particularly focus on the perceived need for help, the different issue areas that arise, and various contact persons, as these aspects, aside from the goal of SHS, have been demonstrated to have a crucial influence on SHS (Karabenick \& Gonida, 2018; Karabenick \& Knapp, 1988, 1991; Makara \& Karabenick, 2013). Currently, studies linking SHS strategies to specific stages of a complete task process are non-existent, and research with a developmental perspective is sparse, even though a development perspective is especially relevant when considering issues related to the need for help and the selection of SHS sources (Karabenick \& Gonida, 2018). Therefore, we examine the issue of whether and in what way SHS strategies change over a longer period and identify the specific SHS strategies that are the most successful in view of the need for help, different issue areas, and various contact persons considering different types. 


\subsection{Social Help Seeking as a Processual Learning Strategy}

Depending on the author, SHS is described as a process that includes five to seven steps. The following seven steps can be defined according to different authors: At the beginning of the process, the student must realise that he or she has a problem (1) and will not make any progress without help (2). Ascertaining that help is needed does not automatically induce SHS behaviour, as motivational, cognitive and social factors mediate students' SHS behaviour in a specific context (Schworm \& Fischer, 2006). If the decision to seek help is made, the student sets an SHS goal (3) that can be executive (i.e. asking for a direct answer or solution) or instrumental (asking for hints) in nature (Karabenick \& Knapp, 1991; Karabenick \& Newman, 2010; Schworm, 2018). The next step is to search for potential helpers (4). This decision is influenced by various characteristics of the possible helper on the one hand, and of the person seeking help, on the other (Ryan, Pintrich \& Midgley, 2001; Ryan \& Shin, 2011; Schworm $\&$ Fischer, 2006). Based on the type of assistance requested (5) and received (6), the learner must ultimately decide whether such assistance has served its purpose or whether he or she should seek further help and in doing so, start a new SHS cycle (7) (Nelson-Le Gall, 1985). These steps may be conducted in a different order, and individual steps can also be undertaken in parallel (Nelson-Le Gall, 1985). Similar to Zimmerman's (2002) self-regulation model, in which reflections serve to decide whether students can continue learning in a certain manner or whether adaptations are necessary, a parallel assumption for the SHS process is that the final evaluation may engender an adaptation of future SHS (Karabenick \& Berger, 2013). For example, if a student could not find the desired help from a particular person, he or she may ask another individual for help in the future (Nelson-Le Gall, 1981). Therefore, SHS places high demands on the reflection of previous processes and consequently on the decision making of the person seeking help.

\subsection{Previous Types of Social Help Seeking and Their Role in Academic Achievement}

Regarding previous research on SHS forms and types, a distinction can be made between variable-centred and person-centred approaches to highlight both the theoretical and the empirical backgrounds. Variable-centred approaches focus on the relationship of the variables themselves, whereas person-centred approaches underscore the subpopulations of people identified by similar value patterns on a set of variables (Finney, Barry, Horst \& Johnston, 2018). By examining the pattern of values across variables, a person is typified in a holistic meaning (Magnusson, 1998). Therefore, the goal of using a person-centred approach is to represent the types (Nagin, 2005) and thereby to provide a "view of the person as a system of interacting components" (Robins, John \& Caspi, 1998, p. 135). In contrast, a variable-centred approach does not provide information on the combination of dimensions within the person, but it establishes relationships between aggregated dimensions (Finney et al., 2018).

Up to now, SHS research within variable-centred approaches mainly distinguishes three forms (reasons or orientations, sometimes also referred to as types) of SHS in the classroom context that chiefly emphasise the goals of learners (e.g. Butler, 1998, 2006; Nadler, 1998; Nelson-Le Gall, 1981; Ryan, Patrick \& Shim, 2005). First, instrumental (autonomous, adaptive, appropriate) SHS highlights the improvement of individual knowledge and competence, and here in-depth learning transpires (Karabenick \& Newman, 2006). Second, executive (expedient, dependent) SHS strives to finalise solutions to avoid exertion. The third form is to avoid SHS, even if help is needed. The last two forms are less conducive to sustainable learning (Karabenick \& Newman, 2010). Thus, SHS not only implies an act of dependence but also represents an adaptive and strategically beneficial process (Butler, 1998; Karabenick, 1998; Nelson-Le Gall, 1981). Given the potential benefit of SHS, various studies in this context have focused on the determinants of persons and situations (Wolters et al., 2003) that affect whether help is sought, for what reasons and by whom (Butler, 1998, 2006; Butler \& Neuman, 1995; Elliot \& Church, 1997; Elliot \& McGregor, 2001; Karabenick, 1998; Nelson-Le Gall, 1981; Ryan \& Pintrich, 1997; Ryan et al., 2001). 
The few studies with person-centred approaches (Finney et al., 2018; Karabenick, 2003), whereby SHS types were analysed, are of particular interest here and are therefore described in more detail. Karabenick (2003) examined students using five HS scales, namely, instrumental and executive help seeking, help-seeking avoidance, help-seeking threat, and formal versus informal help seeking, whereby the latter points to the aspect of SHS. All items were formulated hypothetically in relation to a possible difficulty that might occur (e.g. "Getting help would be one of the first things I would do if I were having trouble in this class" (Karabenick, 2003, p. 55)). On this basis, a hierarchical cluster analysis was conducted, which yielded four types of student SHS: strategic/adaptive/formal (17\%), strategic/adaptive/informal (25\%), non-strategic (36\%) and avoidant (23\%). Although this outcome broadly confirmed the division into the three forms of SHS for the classroom context (e.g. Butler, 2006; Nadler, 1998; Nelson-Le Gall, 1981), it resulted in an expansion by two specific source levels (i.e. informal versus formal). The types were subsequently examined with regard to their differences in achievement. The most clearly identified cluster was the instrumental SHS type (strategic/adaptive/formal) with a preference for help from formal sources (teachers), which had the highest performance level, whereas the avoidant type exhibited the lowest performance level (Karabenick, 2003). Finney et al. (2018) investigated whether they could replicate Karabenick's (2003) four-type solution if they employed a more general measurement of SHS. They initially examined incoming first-year college students using modified items already utilised by Karabenick (2003) and related them to the general school context (i.e. across all classes during one semester). Similar to Karabenick's (2003) approach, the items were formulated in such a way that the need for help should be controlled by the formulation of the question about what the students would do if they needed help (Finney et al., 2018). In addition, the items were verbalised in relation to a hypothetical problem. In contrast to Karabenick (2003), Finney et al. (2018) produced three SHS types and identified only minor differences between the individual types. Hence, the four types from the first study could not be replicated, although the authors recognised a possible reason for this case in the more general measurement of SHS (i.e. across several classes). These reports argue in favour of examining SHS types in a much stronger task-related manner. In a second study with upper class students and the same instruments, Finney et al. (2018) indicated that the types had similar profiles to the types of first-year college students. Additionally, with regard to dissimilarities in achievement, Finney et al. (2018) established that the instrumental and formal source-related SHS dimension was positively related to optimal outcomes and negatively related to non-optimal outcomes; the avoidance, threat, and executive SHS dimensions had inverse relations.

Altogether, the strong orientation toward the goals of SHS in previous research on SHS types in the classroom context becomes clear, which can demonstrate that different forms or types of SHS based on the goals make dissimilar contributions to learning and thus to the achievement of the learners, both with variable- and person-centred approaches (e.g. Butler, 2006; Karabenick, 2003; Ryan et al., 2005). Thus far, the focus has been primarily on the purpose of SHS: to explore the SHS forms and types of learners. We intend to broaden this focus through an in-depth analysis of the need for help, different perceived issue areas and various contact persons, as these factors have also emerged as central influencing factors in SHS.

\subsection{Central Influencing Factors in Social Help Seeking}

The need for help can be considered as a key element to understand the part played by SHS in the learning process (Karabenick \& Knapp, 1991). As awareness of the need for help constitutes the starting point of SHS (Ryan et al., 2001) SHS "should be directly related to the learners' perceived need for help" (Karabenick \& Gonida, 2018, p. 422). When learners are aware of what they need to learn/work effectively, they are able to take action to meet the demands of the task (Nelson-Le Gall, 1981). Karabenick and Knapp (1988) demonstrated the high importance of the learner's need for help in their early analyses of students in various courses. Thus, the need for help was positively related to the frequency of asking for help. Moreover, this relationship was curvilinear (Karabenick \& Knapp, 1988) so that students with a high need and students with a very low need for help were the least likely to seek help. Karabenick and Knapp (1988) attributed the fact that students in great need seek less help to cognitive 
and emotional hindrances, especially helplessness. This curvilinear relationship was also established for the link between the stated need and the grades expected by learners (Karabenick \& Knapp, 1988). In a later study, Karabenick and Knapp (1991) again examined the need for help and the SHS of students. They concluded that the need for help was strongly associated with SHS. If grades were included, the researchers demonstrated that the need for help was inversely related to grades, and that grades were inversely related to SHS. In contrast to their previous study, no significant quadratic but a linear trend could be found for the relationship between help seeking and grades. Hence, Karabenick and Knapp (1991) revealed that learners with a low need for help sought less help and overall performed better, which they attributed to these learners' increased use of learning strategies. Overall, the results indicate that when learners need help, they are more likely to seek it. However, the authors note that the relationships presented merely demonstrated what learners would do if they were confronted with a problem (Karabenick \& Knapp, 1991). The results of studies with variable-centred approaches illustrate the relationship between the perceived need for help and SHS. The inclusion of the perceived need for help in studies of SHS also with person-centred approaches is therefore essential.

If the help is needed and recognised as such, SHS also depends on different contact persons (e.g. Makara \& Karabenick, 2013) who are selected on the basis of the perceived issue area (e.g. Boldero \& Fallon, 1995). Contextual resources can determine the rate and effectiveness of SHS (Karabenick \& Gonida, 2018). Within different courses or tasks, challenges in different sub-topics can appear for which help is needed and sought. Various early studies indicated that different people asked for help depending on the issue area for which help is required. For example, family and peers are primarily asked for help with psychological, personal challenges (Boldero \& Fallon, 1995; Rickwood, 1995; Tinsley, de St. Aubin \& Brown, 1982). However, academic advisors or teachers are more often asked for help with career-related aspects (Tinsley et al., 1982). Therefore, the characteristics of the person providing help (e.g. confidence [Newman, 2000], knowledge [Stroebe, Hewstone, Codol \& Stephenson, 2013] and care [Ryan \& Shim, 2012]) play a central role. Within the challenging task of developing an individual academic paper over a longer period, Huber, Lehmann and Husfeldt (2011) identified different thematic areas that are relevant for writing a school leaving certificate paper and can therefore cause difficulties as well. Most of the pupils turned to the supervisor for challenges regarding the content and structure of the paper. A few students asked the supervisor for help with formulating the research question, formal principles (e.g. footnotes, bibliography, citations) and information sources. In terms of working methods, for questions about the timetable and organisation of work and about writing the paper (writing process), even fewer learners turned to the supervisor. Students were the least likely to ask their supervisors for help with their choice of topic or with overcoming a crisis. The supervisor is evidently not selected as the first contact person for challenges in all of the issue areas. The authors revealed that other contact persons were also used when difficulties arose, including parents and peers. However, the specific issue to which the SHS referred regarding these sources was unclear. From these results with variable-centred approaches, SHS must be viewed in the light of the challenges in different areas, and the choice of the persons providing help is based on what kind of issue is causing difficulty.

\subsection{Research Deficits}

In summary, SHS has a strong social-interactive character, in which the need for help of the person seeking assistance as well as the context (task, issue area) and the contextual resources (contact persons) based on this context can have a crucial impact. Previous research on SHS types reported similar results across different school levels, with instrumental SHS types with a preference for help from formal sources performing better than executive SHS types or avoiders. There has been a strong focus to date on the goals of SHS and potential helpers in the classroom context, both in person-centred (Finney et al., 2018; Karabenick, 2003) and variable-centred approaches (Butler, 1998, 2006; Butler \& Neuman, 1995; Elliot \& Church, 1997; Elliot \& McGregor, 2001; Nelson-Le Gall, 1981; Ryan \& Pintrich, 1997; Ryan et al., 2001). However, several research desiderata can be identified. The few studies that dealt with SHS types in a person-centred approach usually included only one measurement point in their analyses or merely depicted a cross-section and recorded SHS in relation to different university courses 
across several different tasks. Today, few studies with a developmental perspective are available (Karabenick \& Gonida, 2018), and reports argue in favour of examining SHS types in a much stronger taskrelated manner. Furthermore, the need for help has a connection with SHS. This factor must be considered in the formation of SHS types. Thus far, this case has hardly occurred in explicit terms. The items in the investigations to date were formulated hypothetically in relation to a possible undefined difficulty that might occur. The perceived level of need was not integrated. Additionally, SHS can vary based on challenges in diverse task and issue areas. Therefore, SHS must be considered as a task-situated process in relation to the difficulties actually experienced in different issue areas. Moreover, most of the analyses especially focus on SHS behaviour in the classroom context. As learning transpires not only in the classroom, SHS processes should also be examined for educational tasks beyond the context of regular instruction that allow for a high degree of self-regulation; one example is writing an academic paper during extracurricular time, in which teachers or peers are not always present but other contacts may play a role.

\subsection{Present Study: Questions and Hypotheses}

The aim of this study is to extend previous investigations by adopting a task-specific, longitudinal perspective and focusing on SHS in the context of a real, challenging, long-term, academic task outside of regular classroom instruction. The study extends previous research by examining SHS strategies along different types (person-centred approach), focusing on the perceived need for help, various sources and specific areas in which challenges can arise. Three questions are investigated. First, do different types of SHS strategies exist in each task stage of developing an academic paper outside the classroom context (Q1)? Due to the theory on SHS with dissimilar decision possibilities (Nelson-Le Gall, 1981), different characteristics of influence on the part of the person providing help (e.g. Ryan \& Shim, 2012), and as students are confronted with various challenges in each creation stage (Backhaus $\&$ Tuor, 2008), we expect to find diverse SHS types per task stage (hypothesis 1).

Second, what is the extent to which the types of SHS strategies change during the course of the creation process (Q2)? Following Zimmerman (2002), we assume that experiences in one stage can result in a change in SHS in a subsequent stage. Thus, despite the assumptions of Finney et al. (2018), our presupposition is the changeability of SHS behaviour over time based on different sub-tasks per stage and previous experiences. Consequently, we hypothesise that students may transfer between different SHS types (hypothesis 2). Furthermore, assumptions in an explorative manner can be made regarding possible changes, as previous theoretical and empirical foundations are insufficient: Students who received help from their paper supervisor that they found useful in the first stage need less help with the academic paper in the following stages (hypothesis 3); however, if they do not discuss the concept broadly with the supervisor, these students will need help at a later stage (hypothesis 4). We also expect that some students will need help throughout all stages, relating to different issues, and will ask various contact persons for help (hypothesis 5).

Third, what is the degree of importance of these SHS types per task stage in academic achievement (Q3)? Based on previous findings of both variable-centred (Butler, 1998, 2006; Karabenick \& Knapp, 1988, 1991; Nadler, 1998; Nelson-Le Gall, 1981; Ryan et al., 2005) and person-centred approaches (Finney et al., 2018; Karabenick, 2003), we assume that the SHS types are ultimately related to different academic achievement (hypothesis 6). 


\section{Context and Methods}

\subsection{Context}

In Switzerland, where this study was conducted, the upper secondary school level has different tiers that are oriented toward various professional tracks. Grammar schools (ISCED levels 3-4) represent the track with a strong emphasis on academic learning that prepares students for university. Toward the end of this track, students must write a compulsory school leaving certificate paper, which is referred to as the Matura thesis. This academic paper significantly contributes to the grade on the final exit examination, which in turn, if passed, guarantees unrestricted admission (with the exception of medical studies in Switzerland) to a university of applied sciences or university (Swiss Federal Council \& EDK, 1995). After completion of the upper secondary school leaving certificate, students have the ability to access new knowledge, develop their curiosity, imagination and communication skills, and work alone and in groups (Swiss Federal Council \& EDK, 1995, Art. 5). As the Matura thesis is a demanding task, it requires self-regulated learning. However, it also has the potential to promote self-regulated learning competencies (Huber, Husfeldt, Lehmann \& Quesel, 2008). Students are given approximately one year's time to complete their papers. The papers are written individually or in groups, outside of class during extracurricular time. The developing process of the Matura thesis consists of three task stages, each containing different key activities. The first stage is concept development (t1), in which a research question is identified; the learners have ample freedom to select the topic and plan implementation to answer the research question. The second phase refers to the implementation stage (t2), in which students start creating their paper. In the final stage (t3), students finish their Matura thesis, evaluate and revise it, and finally submit it.

\subsection{Participants}

All study procedures complied with the human subjects' guidelines of the Swiss National Science Foundation. Students had the opportunity to withdraw their participation at any time. This longitudinal study began with 1,250 students $(55.9 \%$ female) with an average age of $17.5(S D=.81)$ at 12 urban and rural upper secondary schools. The number of participants was later reduced based on the criteria below.

To determine possible changes between SHS types and task stages, we had to reduce the sample based on two arguments. First, we included in the analyses only those students who filled out all three online questionnaires $(\mathrm{t} 1, \mathrm{t} 2, \mathrm{t} 3)$ needed for this study. This criterion provided a longitudinal sample of $\mathrm{n}=713(63.0 \%$ female $)$ students with an average age of $M=17.4(S D=.76)$ over three measurement points. Second, the academic paper can be written alone or in a group. To be able to compare the HS of individuals, we were interested in those students who wrote their paper on their own. We consequently excluded those students who wrote their thesis in pairs or groups. This criterion resulted in the reduction of 110 students.

The final sample of this study consisted of $\mathrm{n}=603$ students ( $62.9 \%$ female) with an average age of $17.3(S D=.71)$. Up to $91.7 \%$ of these learners stated that they were born in Switzerland, and $86.4 \%$ specified that they most often spoke German/Swiss German at home. We compared the sample of this study with the characteristics of the population of students in grammar schools in the German-speaking part of Switzerland. The sample reflected the population of this type of school with respect to gender, age, nationality and native language.

\subsection{Measurements}

The participants answered all the items in the online self-report questionnaires. For these analyses, the perceived frequency of asking the supervisor, family and peers for help, as well as the issue 
areas and the related contact persons were quantified at three measurement times, retrospectively for one task stage each. The perceived need for help was calculated at one measurement time, retrospectively for the three task stages of creating the academic paper. This approach resulted in 72 collected SHS variables (24 variables per stage). All of the aspects included are explained in more detail in the following sections.

\subsubsection{Perceived need for help}

After the students had submitted their Matura thesis (t3), we asked them about their retrospective perceived need for help in the different stages of the creation process. We asked, "To what extent were you reliant on help to continue working through the whole process?" ( 3 items, 1 item for each stage: "During the [fill in the stage] stage, I was...."). The responses ranged from 1 (not at all reliant on help) to 6 (entirely reliant on help).

\subsubsection{Perceived frequency of asking for help}

The perceived frequency of asking for help was measured thrice with the following question during the entire process, retrospectively for each stage ( $\mathrm{t} 1, \mathrm{t} 2, \mathrm{t} 3)$ : "How often did you request help from the following persons?" Participants responded on a 6-point Likert scale from 1 (never) to 6 (very often) for supervisor, family and peers, and it was respectively adjusted for each creation stage $(3 \times 3$ items).

\subsubsection{Issue areas and contact persons}

To identify the individuals from whom the students asked for help relating to specific issue areas, we asked them the following question retrospectively for each stage ( $\mathrm{t} 1, \mathrm{t} 2, \mathrm{t} 3)$ at three different points in time: "Who did you ask for help concerning the following issue areas?" We gave the students different possible contact persons (nobody, supervisor (formal), family (informal), peers (informal), and others) whom they could select relating to different given issue areas $(5 \times 4 \times 3$ items). Most of the issue areas were obtained from Huber et al.'s (2011) study, as they proved to be relevant for writing a school leaving certificate paper. However, to ensure the comparability of the types across the phases, those issue areas that turned out to be relevant and thus possibly leading to difficulties for all three phases were integrated into the present analyses, namely, information source, working methods, timetable and organisation of the paper (factual issue areas), and motivation and resolving crises (motivational issue areas). For this question, multiple answers were possible $(1=$ selected, $2=$ not selected $)$.

\subsubsection{Academic achievement}

Academic achievement was also recorded as the students' grades on their academic papers. The paper supervisors and the second assessors evaluated the papers. We were given access to the students' official grades, which in Switzerland range from 1 to 6, with 6 being the highest grade.

\subsection{Statistical analyses}

As a person-centred approach, we conducted latent class analyses (LCA) to ascertain the existence of different SHS types at each task stage of generating an academic school leaving certificate paper. Latent class analysis is a statistical method for classifying individuals into homogeneous subgroups (latent classes) (Finch \& Bronk, 2011). To calculate the results of the LCA, we used Mplus Version 8.1 (Muthén \& Muthén, 1998-2017). To consider missing values, the full information maximum likelihood method (FIML) was used. The proportion of missing values of the variables was on average $1.99 \%$ (min $=0.50 \%$, $\max =5.14 \%$ ). The maximum likelihood robust estimator (MLR) was used to account for a possible deviation from the multivariate normal distribution. With the categorical command in Mplus, we specified that the issue area and contact person items were ordered categorical (dichotomous in this case) variables, whereas all the other variables (perceived need for help, perceived frequency of asking for help) were treated as metric variables. We were able to conduct a mixed distribution analysis (LCA 
in this case) in Mplus by using the command analysis of type = mixture. With mixed distribution analysis, we assumed that the population of students was composed of different subgroups (latent classes, HS types). The model quality statistics and parameter estimates of the LCA were determined in Mplus using the maximum likelihood estimation method. The log-likelihood value is a measure of the probability of the data provided by the model, and it serves as a basis for the calculation of further model fit tests or indices (Finch \& Bronk, 2011). As the final number of classes is unknown beforehand, different models with a changing number of classes have to be tested and compared in terms of various statistical and non-statistical criteria (sample size, interpretability of the classes, average latent class probabilities). The Entropy (E) assesses the quality of the measurement as a whole (Asparouhov \& Muthén, 2014), and it should have a value greater than .80 (Rost, 2006). Furthermore, the values of the Akaike information criterion (AIC) and of the Bayesian information criterion (BIC) were included in the analyses, whereby the lower values correspond to the better fitting model (Geiser, 2011). The Lo-Mendell-Rubin (LMR) and the bootstrap likelihood ratio test (BLR) were also utilised to identify the suitable number of classes. If the LMR and the BLR tests are significant, the model with $\mathrm{k}$ classes represents the data better than the model with k-1 classes (Finch \& Bronk, 2011).

The differences between the classes per stage regarding perceived need for help, perceived frequency of asking for help, issue areas and contact persons, and achievement were analysed using nonparametric methods, namely, the Kruskal-Wallis test and post hoc Dunn-Bonferroni test for categorical and metric variables (Martens, 2003), as the data contained outlier values that were retained due to inconstancy (Sheskin, 2011). The Kruskal-Wallis H test is based on rank numbers assigned to individual characteristic values. Finally, the sums of the rank numbers were calculated for each group (SHS type per stage) and were analysed for significant differences (Martens, 2003).

We conducted a latent transition analysis (LTA) to examine the changes in the course of the learning process. Latent transition analysis can be considered as a longitudinal extension of the LCA. It uses an autoregressive relationship to link the latent class variables of several measurement points (Muthén \& Asparouhov, 2011). The latent transition probabilities, which are of particular interest in the analyses of the LTA results, indicate the probability of being assigned to a specific class at time $t$ based on the assignment to a class at time t-1 (Muthén \& Asparouhov, 2011). Further details can be found in the next section.

\section{Results}

\subsection{Descriptive Statistics}

Table 1 presents the descriptive statistics for all categorical variables. The values represent the percentages of selected contact persons per issue area and the measurement points. Table 2 presents the descriptive statistics for all metric variables. 
Table 1

Descriptive Statistics for the Categorical Variables

\begin{tabular}{|c|c|c|c|c|}
\hline & & $\mathrm{t} 1(\mathrm{n}=596)$ & $\mathrm{t} 2(\mathrm{n}=593)$ & $\mathrm{t} 3(\mathrm{n}=599)$ \\
\hline & & Selected \% & Selected \% & Selected \% \\
\hline \multirow{5}{*}{ Information source } & Nobody & 27.2 & 32.2 & 46.4 \\
\hline & Supervisor & 47.5 & 55.8 & 28.2 \\
\hline & Family & 27.2 & 25.0 & 20.4 \\
\hline & Peers & 6.7 & 5.9 & 5.5 \\
\hline & Others & 21.1 & 30.7 & 20.4 \\
\hline \multirow{5}{*}{ Working methods } & Nobody & 30.5 & 42.0 & 49.1 \\
\hline & Supervisor & 55.5 & 44.7 & 25.5 \\
\hline & Family & 20.5 & 22.3 & 23.0 \\
\hline & Peers & 10.1 & 7.8 & 10.7 \\
\hline & Others & 7.9 & 9.4 & 7.8 \\
\hline \multirow{5}{*}{ Timetable and organisation of work } & Nobody & 38.4 & 49.2 & 67.9 \\
\hline & Supervisor & 46.5 & 38.3 & 12.0 \\
\hline & Family & 18.8 & 16.7 & 19.0 \\
\hline & Peers & 10.2 & 6.6 & 6.5 \\
\hline & Others & 5.2 & 5.4 & 3.2 \\
\hline \multirow{5}{*}{ Motivation and resolving crises } & Nobody & 38.3 & 34.4 & 32.4 \\
\hline & Supervisor & 12.8 & 12.5 & 5.2 \\
\hline & Family & 44.5 & 50.1 & 54.9 \\
\hline & Peers & 25.2 & 25.6 & 26.0 \\
\hline & Others & 8.9 & 13.2 & 15.0 \\
\hline
\end{tabular}

Note. $\mathrm{t} 1$ = concept development stage; $\mathrm{t} 2$ = implementation stage; $\mathrm{t} 3$ = final stage; $\mathrm{n}=$ number of cases; $100 \%$ minus the percentage of the selected response option corresponds to the percentage of the not selected response option. 
Table 2

Descriptive Statistics for the Metric Variables

\begin{tabular}{|c|c|c|c|c|c|}
\hline & & $\mathrm{t}$ & $\mathrm{n}$ & $M$ & $S D$ \\
\hline & & $\mathrm{t} 1$ & 594 & 3.49 & 1.18 \\
\hline \multirow[t]{2}{*}{ Perceived need for help } & & $\mathrm{t} 2$ & 595 & 3.34 & 1.07 \\
\hline & & $\mathrm{t} 3$ & 597 & 3.99 & 1.08 \\
\hline \multirow{9}{*}{ Perceived frequency of asking for help } & Supervisor & & 588 & 3.85 & 1.10 \\
\hline & Family & $\mathrm{t} 1$ & 586 & 3.48 & 1.58 \\
\hline & Peers & & 585 & 2.53 & 1.35 \\
\hline & Supervisor & & 597 & 3.79 & 1.04 \\
\hline & Family & $\mathrm{t} 2$ & 594 & 3.44 & 1.53 \\
\hline & Peers & & 572 & 2.26 & 1.30 \\
\hline & Supervisor & & 600 & 3.29 & 1.29 \\
\hline & Family & $\mathrm{t} 3$ & 597 & 4.23 & 1.40 \\
\hline & Peers & & 596 & 2.50 & 1.43 \\
\hline Academic achievement & & & 560 & 5.22 & 0.59 \\
\hline
\end{tabular}

Note. $\mathrm{t} 1$ = concept development stage; $\mathrm{t} 2$ = implementation stage; $\mathrm{t} 3$ = final stage; $\mathrm{n}=$ number of cases; $M=$ mean; $S D=$ standard deviation; perceived need for help: $1=$ not at all reliant on help, $6=$ entirely reliant on help; perceived frequency of asking for help: 1 = never, 6 = very often; academic achievement: $1=$ lowest grade, $6=$ highest grade.

\subsection{Identification and Description of the Help-Seeking Types per Stage (LCA)}

Table 3 lists the models that were best suited to the data and their criteria to statistically evaluate the model fit for the different class solutions generated by the LCA. The analyses were based on the aforementioned 72 collected SHS variables (i.e. 24 variables per stage), referring to perceived need for help, perceived frequency of asking for help, and the issue areas and contact persons (see section 2.3). 
Table 3

Statistical Fit Indices for the Most Appropriate Class Solutions at Different Measurement Times

\begin{tabular}{|c|c|c|c|c|c|c|c|c|}
\hline $\mathrm{t}$ & Model & $\mathrm{BIC}$ & AIC & $\mathrm{E}$ & $\mathrm{BE}$ & $\begin{array}{c}\text { Average latent class } \\
\text { probabilities }\end{array}$ & $p_{\text {LMR }}$ & $p_{\text {BLR }}$ \\
\hline \multirow[t]{4}{*}{$\mathrm{t} 1$} & 2-class & 19202.034 & 18968.732 & 0.778 & 0 & $0.943,0.927$ & $\mathrm{p}<.001$ & $\mathrm{p}<.001$ \\
\hline & 3-class & 18948.679 & 18605.329 & 0.939 & 7 & $0.989,0.953,0.979$ & $\mathrm{p}<.001$ & $\mathrm{p}<.001$ \\
\hline & 4-class & 18814.661 & 18361.263 & 0.931 & 12 & $\begin{array}{l}0.966,0.939,0.994 \\
0.976\end{array}$ & $\mathrm{p}<.001$ & $\mathrm{p}<.001$ \\
\hline & 5-class & 18764.535 & 18201.089 & 0.922 & 16 & $\begin{array}{l}0.943,0.995,0.988 \\
0.948,0.892\end{array}$ & $\mathrm{p}=.320$ & \\
\hline \multirow[t]{5}{*}{$\mathrm{t} 2$} & 2-class & 18665.312 & 18432.010 & 0.848 & 0 & $0.958,0.953$ & $\mathrm{p}<.001$ & $\mathrm{p}<.001$ \\
\hline & 3-class & 18396.259 & 18052.910 & 0.923 & 5 & $0.978,0.954,0.964$ & $\mathrm{p}<.001$ & $\mathrm{p}<.001$ \\
\hline & 4-class & 18283.625 & 17830.228 & 0.923 & 17 & $\begin{array}{l}0.959,0.953,0.979 \\
0.948\end{array}$ & $\mathrm{p}<.001$ & $\mathrm{p}<.001$ \\
\hline & 5-class & 18178.047 & 17614.602 & 0.935 & 20 & $\begin{array}{l}0.969,0.989,0.902 \\
0.962,0.954\end{array}$ & $\mathrm{p}<.001$ & $\mathrm{p}<.001$ \\
\hline & 6-class & 18110.240 & 17436.746 & 0.913 & 22 & $\begin{array}{l}0.962,0.968,0.921 \\
0.924,0.961,0.897\end{array}$ & $\mathrm{p}=.196$ & \\
\hline \multirow[t]{6}{*}{$\mathrm{t} 3$} & 2-class & 18342.240 & 18108.938 & 0.842 & 4 & $0.948,0.945$ & $\mathrm{p}<.001$ & $\mathrm{p}<.001$ \\
\hline & 3-class & 18041.834 & 17698.485 & 0.935 & 9 & $0.986,0.978,0.996$ & $\mathrm{p}<.001$ & $\mathrm{p}<.001$ \\
\hline & 4-class & 17919.453 & 17466.056 & 0.983 & 17 & $\begin{array}{l}0.990,0.986,0.995 \\
0.896\end{array}$ & $\mathrm{p}<.001$ & $\mathrm{p}<.001$ \\
\hline & 5-class & 17845.115 & 17281.670 & 0.977 & 31 & $\begin{array}{l}0.974,0.999,0.995 \\
0.976,0.990\end{array}$ & $\mathrm{p}<.001$ & $\mathrm{p}<.001$ \\
\hline & 6-class & 17824.408 & 17150.915 & 0.974 & 38 & $\begin{array}{l}0.972,0.965,0.990 \\
0.998,1.000,0.989\end{array}$ & $\mathrm{p}<.001$ & $\mathrm{p}<.001$ \\
\hline & 7-class & 17828.345 & 17044.804 & 0.954 & 45 & $\begin{array}{l}0.970,0.983,0.899 \\
0.948,0.998,0.976 \\
0.978\end{array}$ & $\mathrm{p}=.143$ & \\
\hline
\end{tabular}

Note. $\mathrm{t} 1$ = concept development stage; $\mathrm{t} 2=$ implementation stage; $\mathrm{t} 3=$ final stage; $\mathrm{BIC}=$ Bayesian; $\mathrm{AIC}=\mathrm{Akaike} ; \mathrm{E}=\mathrm{en}-$ tropy; $\mathrm{BE}=$ boundary estimates (logit thresholds that were set at the extreme values -15.000 and 15.000 ); $p_{\mathrm{LMR}}=$ significance of the Lo-Mendell-Rubin; $p_{\mathrm{BLR}}=$ significance of the bootstrap likelihood ratio test.

Initially, the 4-class solution for measurement point t1, the 5-class solution for $\mathrm{t} 2$ and the 6-class solution for $\mathrm{t} 3$ seem to be ideal (see Table 3 ). However, closer inspection apparently indicated that these solutions contained many boundary estimates, thus making interpretation difficult. Even though the BIC is the most frequently used decision criterion, it sometimes refers to theoretically implausible solutions, especially for large samples, and results in the overestimation of class numbers (Specht, Luhmann \& Geiser, 2014). Hence, the criteria were only evaluated in combination. The 3-class solution is preferred at all measurement times due to the interpretability and uniqueness of the classes, statistical fit indices, average latent class probabilities and the smallest number of boundary estimates.

The following sections describe the SHS types in more detail for each stage of the creation process of the Matura thesis. First, the differences between the classes per measurement point are listed. 
As both metric and binary individual items were included in the LCA, the results are then listed separately for each task stage.

3.2.1. Social help-seeking types in the concept development stage (t1)

The first classes refer to the concept development stage. Three classes could be identified, which mainly differ in the categorical and metric variables examined (see Table 4).

Table 4

Differences Between Classes in the Concept Development Stage (t1)

\begin{tabular}{|c|c|c|c|c|c|c|}
\hline \multicolumn{2}{|l|}{$n=596$} & Class & Mean rank & $\chi^{2}$ & $p$ & Class differences \\
\hline \multicolumn{7}{|c|}{ Categorical class variables } \\
\hline \multirow{15}{*}{ Information source } & \multirow{3}{*}{ Nobody } & 1 & 312.21 & \multirow{3}{*}{53.040} & \multirow{3}{*}{$<.001$} & \multirow{3}{*}{$1-2,1-3,2-3$} \\
\hline & & 2 & 240.68 & & & \\
\hline & & 3 & 330.36 & & & \\
\hline & \multirow{3}{*}{ Supervisor } & 1 & 264.56 & \multirow{3}{*}{44.889} & \multirow{3}{*}{$<.001$} & \multirow{3}{*}{$1-3,2-3$} \\
\hline & & 2 & 358.73 & & & \\
\hline & & 3 & 273.75 & & & \\
\hline & \multirow{3}{*}{ Family } & 1 & 302.60 & \multirow{3}{*}{39.034} & \multirow{3}{*}{$<.001$} & \multirow{9}{*}{$1-3,2-3$} \\
\hline & & 2 & 344.44 & & & \\
\hline & & 3 & 266.57 & & & \\
\hline & \multirow{3}{*}{ Peers } & 1 & 299.27 & \multirow{3}{*}{6.314} & \multirow{3}{*}{.043} & \\
\hline & & 2 & 308.94 & & & \\
\hline & & 3 & 291.31 & & & \\
\hline & \multirow{3}{*}{ Others } & 1 & 299.02 & \multirow{3}{*}{7.162} & \multirow{3}{*}{.028} & \\
\hline & & 2 & 316.88 & & & \\
\hline & & 3 & 286.22 & & & \\
\hline \multirow{10}{*}{ Working methods } & \multirow{3}{*}{ Nobody } & 1 & 389.50 & \multirow{3}{*}{460.046} & \multirow{3}{*}{$<.001$} & \multirow{3}{*}{$1-2,1-3,2-3$} \\
\hline & & 2 & 120.18 & & & \\
\hline & & 3 & 375.91 & & & \\
\hline & \multirow{3}{*}{ Supervisor } & 1 & 216.47 & \multirow{4}{*}{296.598} & \multirow{3}{*}{$<.001$} & \multirow{3}{*}{$1-3,2-3$} \\
\hline & & 2 & 452.84 & & & \\
\hline & & 3 & 232.92 & & & \\
\hline & \multirow{3}{*}{ Family } & 1 & 294.61 & & & \\
\hline & & 2 & 359.50 & \multirow[t]{2}{*}{77.099} & $<.001$ & $1-3,2-3$ \\
\hline & & 3 & 260.17 & & & \\
\hline & Peers & 1 & 285.24 & 30.457 & $<.001$ & $1-2,1-3$ \\
\hline
\end{tabular}




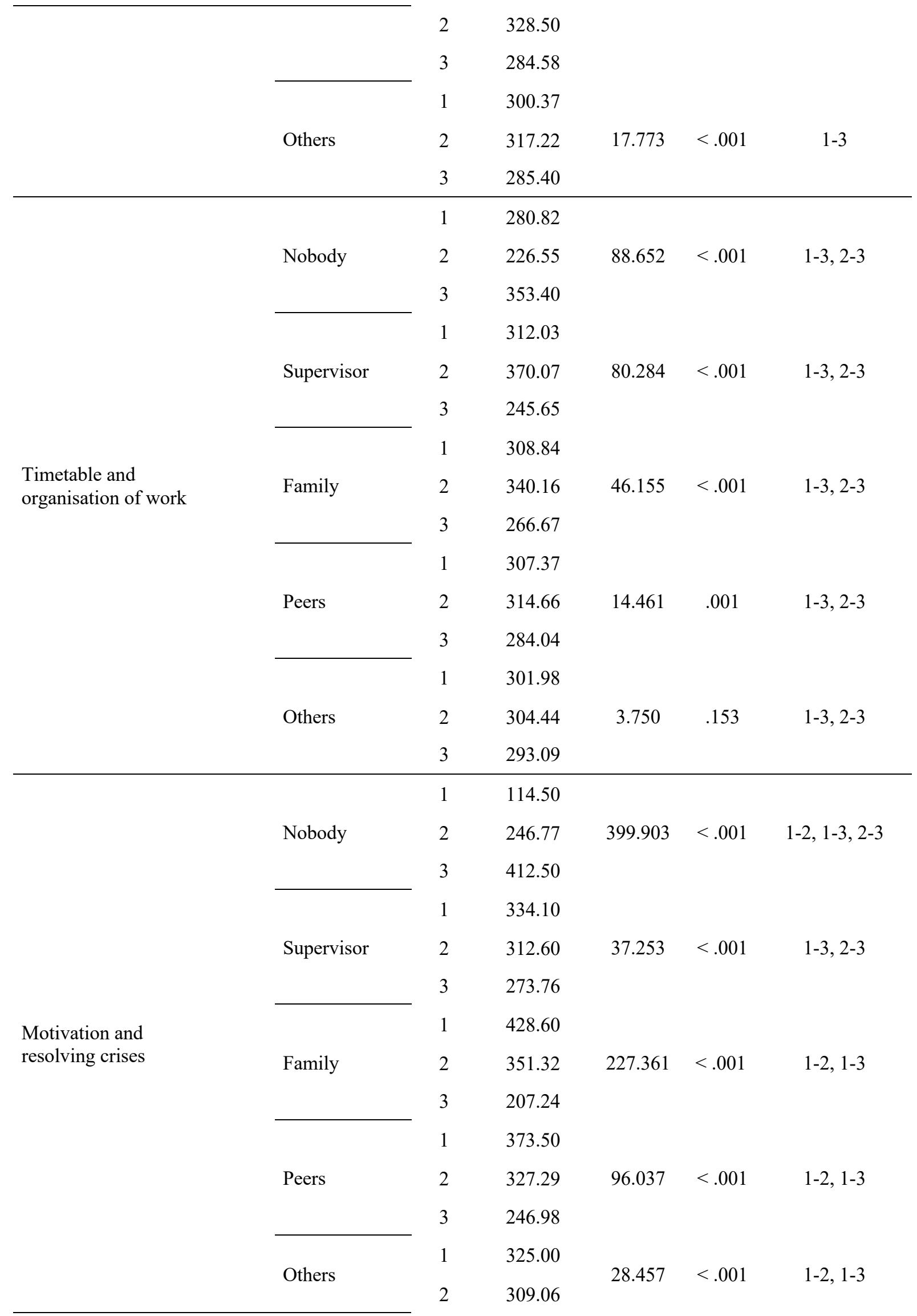




\begin{tabular}{|c|c|c|c|c|c|c|}
\hline & & 3 & 280.04 & & & \\
\hline \multicolumn{7}{|l|}{ Metric class variables } \\
\hline \multirow{3}{*}{ Perceived need for help } & & 1 & 301.15 & \multirow{3}{*}{12.610} & \multirow{3}{*}{.002} & \multirow{3}{*}{$1-2,1-3,2-3$} \\
\hline & & 2 & 263.06 & & & \\
\hline & & 3 & 318.46 & & & \\
\hline \multirow{9}{*}{ Perceived frequency of asking } & \multirow{3}{*}{ Supervisor } & 1 & 305.16 & \multirow{3}{*}{18.862} & \multirow{3}{*}{$<.001$} & \multirow{3}{*}{$1-3,2-3$} \\
\hline & & 2 & 251.46 & & & \\
\hline & & 3 & 317.12 & & & \\
\hline & \multirow{3}{*}{ Family } & 1 & 242.30 & \multirow{3}{*}{59.828} & \multirow{3}{*}{$<.001$} & \multirow{3}{*}{$1-2,1-3,2-3$} \\
\hline & & 2 & 242.35 & & & \\
\hline & & 3 & 347.91 & & & \\
\hline & \multirow{3}{*}{ Peers } & 1 & 261.81 & \multirow{3}{*}{15.523} & \multirow{3}{*}{.001} & \multirow{3}{*}{$1-2,1-3$} \\
\hline & & 2 & 270.91 & & & \\
\hline & & 3 & 320.32 & & & \\
\hline
\end{tabular}

Note. $\chi^{2}=$ chi-square $(d f=2)$; Kruskal-Wallis test and post hoc Dunn-Bonferroni test for categorical and metric variables.

Figure 1 shows the mean values of the metric class variables for the three latent classes, and Table 5 presents the respective probabilities for the categorical class variables. The first class containing $20.6 \%(n=124)$ of the students surveyed (see Figure 1) mostly had values that were in-between the ranges of the other classes. With an average value of $M=3.53(S D=1.16)$, they had a self-reported dependence on help that ranked above the second class and below the third class. Similarly, the selfreported perceived frequency of asking for help was in the middle range for the supervisor $(M=3.89$, $S D=1.08)$ and for the family $(M=3.01, S D=1.49)$ compared to the other classes. They exhibited a slightly higher value $(M=2.78, S D=1.33)$ only regarding perceived frequency of asking peers for help. However, they had the highest value on seeking help from the supervisor. This result already indicated that students in this first class especially asked their supervisor for help, if at all. The results of the categorical variables (see Table 5) confirmed this initial assumption and revealed that for the factual issue areas (information source and working methods), the primary person asked for help was the supervisor. These results explicated the class that we named factual supervisor-focused. 


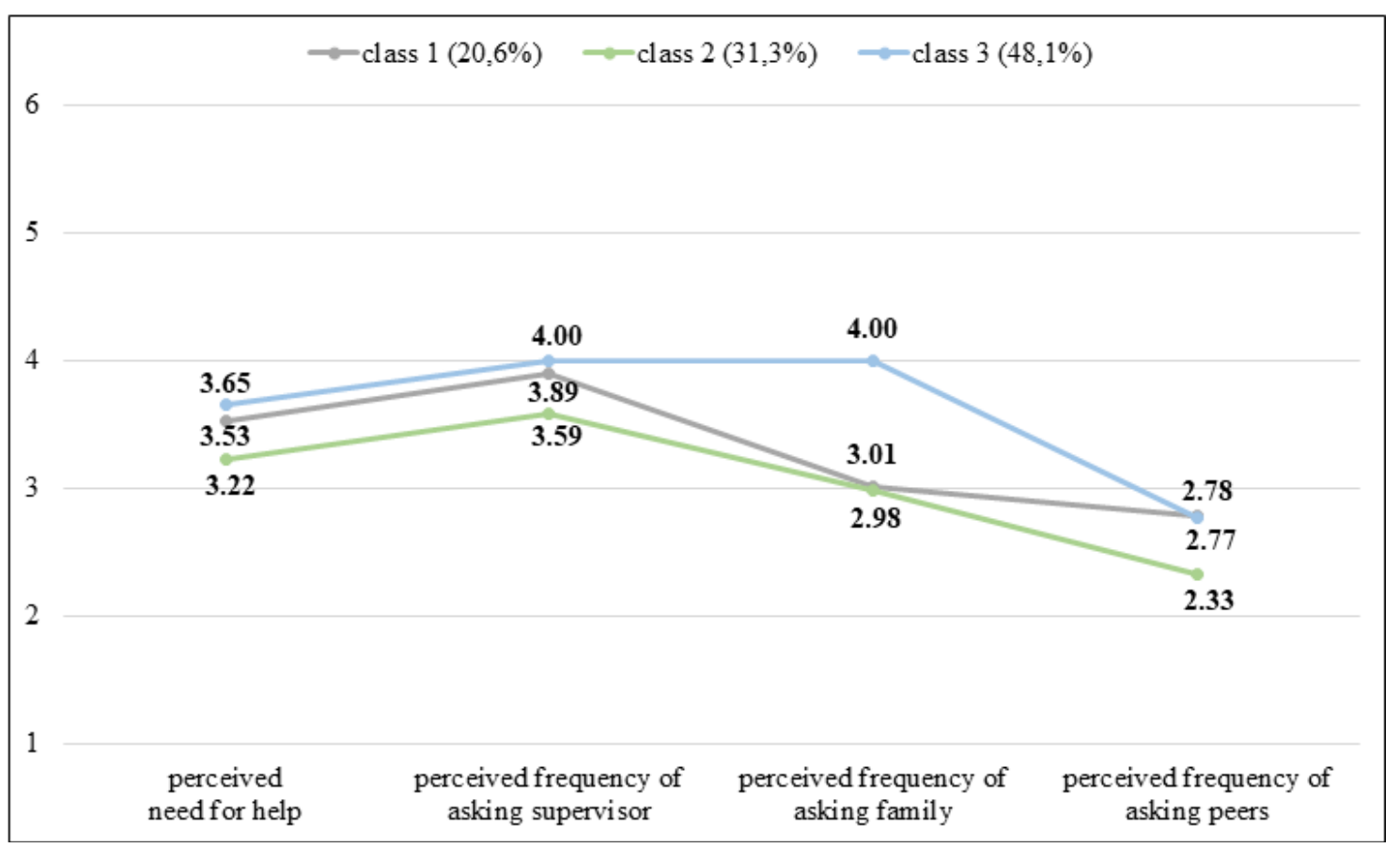

Figure 1. Mean values of the respective metric class variables in the concept development stage ( $\mathrm{t} 1, \mathrm{n}$ =603). Perceived need for help: $1=$ not at all reliant on help, $6=$ entirely reliant on help. Perceived frequency of asking: 1 = never, 6 =very often. Class $1=$ factual supervisor-focused, class $2=$ independents, class 3 = factual supervisor-focused and motivational family-focused.

The second class containing 31.3\% $(n=189)$ of the students (see Figure 1$)$ had the overall lowest values compared to the other classes in the concept development stage. These students gained an average value of $M=3.22$ ( $\mathrm{SD}=1.16)$. According to self-reports, the students were minimally dependent on help. The perceived frequency of asking for help from the supervisor revealed the lowest value for all the classes with an average value of $M=3.59(S D=1.08)$. The values for the perceived frequency of asking the family $M=2.98(S D=1.49)$ and peers $M=2.33(S D=1.33)$ for help were the lowest in comparison to the other classes as well. For motivational aspects (motivation and resolving crises), the students did not ask anyone for help (see Table 5). These findings explained the class that we named independents.

The third class (see Figure 1), which contains 48.1\% $(n=290)$ of the students, was the largest of the three classes in the concept development stage. Compared to the other two classes, the students in the third class stated on average that they were most dependent on help $(M=3.65, \mathrm{SD}=1.16)$ and that they sought help most from the supervisor $(M=4.00, \mathrm{SD}=1.08)$ and the family $(M=4.00, S D=$ $1.49)$. This group was found in a middle range $(M=2.77, S D=1.33)$ only when seeking help from peers. For factual issue areas (information source, working methods, and timetable and organisation of work, see Table 5), the students in this group stated that they turned to supervisors. In contrast, for motivational aspects (motivation and resolving crises), the family was the primary contact person. These outcomes clarified the class name factual supervisor-focused and motivational family-focused. 
Table 5

Probabilities for the Respective Categorical Class Variables in the Concept Development Stage (t1)

\begin{tabular}{|c|c|c|c|c|}
\hline \multirow[t]{2}{*}{$\mathrm{n}=603$} & & \multicolumn{3}{|c|}{ Probability of selecting response option } \\
\hline & & Class $1(20.6 \%)$ & Class $2(31.7 \%)$ & Class $3(47.8 \%)$ \\
\hline \multirow{5}{*}{ Information source } & Nobody & 0.224 & 0.474 & 0.162 \\
\hline & Supervisor & 0.590 & 0.285 & 0.548 \\
\hline & Family & 0.260 & 0.119 & 0.376 \\
\hline & Peers & 0.065 & 0.032 & 0.090 \\
\hline & Others & 0.212 & 0.150 & 0.251 \\
\hline \multirow{5}{*}{ Working methods } & Nobody & 0.000 & 0.907 & 0.047 \\
\hline & Supervisor & 0.863 & 0.049 & 0.763 \\
\hline & Family & 0.200 & 0.000 & 0.330 \\
\hline & Peers & 0.147 & 0.000 & 0.146 \\
\hline & Others & 0.070 & 0.020 & 0.120 \\
\hline \multirow{5}{*}{$\begin{array}{l}\text { Timetable and organisation } \\
\text { of work }\end{array}$} & Nobody & 0.440 & 0.639 & 0.196 \\
\hline & Supervisor & 0.422 & 0.225 & 0.638 \\
\hline & Family & 0.155 & 0.049 & 0.292 \\
\hline & Peers & 0.073 & 0.053 & 0.147 \\
\hline & Others & 0.039 & 0.035 & 0.068 \\
\hline \multirow{5}{*}{ Motivation and resolving crises } & Nobody & 1.000 & 0.568 & 0.000 \\
\hline & Supervisor & 0.009 & 0.080 & 0.209 \\
\hline & Family & 0.009 & 0.274 & 0.740 \\
\hline & Peers & 0.000 & 0.157 & 0.420 \\
\hline & Others & 0.000 & 0.059 & 0.146 \\
\hline
\end{tabular}

Note. Class 1 = factual supervisor-focused; Class 2 = independents; Class 3 = factual supervisor-focused and motivational family-focused; in bold type $=$ probabilities with a value $>0.500$.

\subsubsection{Social help-seeking types in the implementation stage ( $t 2)$}

Three classes could also be found for the implementation stage. Table 6 shows the differences between classes in the implementation stage. As in the concept development stage, the metric class variables were examined in more detail before exploring the categorical variables for each of the classes at this stage. Figure 2 shows the mean values of the metric class variables for the three latent classes, and Table 7 presents the respective probabilities for the categorical class variables.

The first class containing $31.9 \%(n=192)$ of the students (see Figure 2$)$ had the lowest overall values compared to the other classes. With an average value of $M=2.98(S D=1.02)$, students in this class had a low self-reported perceived need for help. The mean values for perceived frequency of seeking help for the two contact groups family $(M=2.78, S D=1.44)$ and peers $(M=1.92, S D=1.27)$ were the lowest overall that could be found at this stage. The mean value for self-reported perceived frequency of asking for help from the supervisor was at a medium level $(M=3.64, S D=1.02)$ compared to the 
others. Once again, this finding could be confirmed by the probability table (see Table 7), which showed that the students in the first class of this stage had individually indicated that they had not asked anyone for help. This case had already emerged in the concept development stage, and no value above 0.50 could be found for the issue area 'information source'. For this reason, this class was called independents.

Table 6

Differences Between Classes in the Implementation Stage (t2)

\begin{tabular}{|c|c|c|c|c|c|c|}
\hline \multicolumn{2}{|l|}{$n=603$} & Class & Mean rank & $\chi^{2}$ & $p$ & Class differences \\
\hline \multicolumn{7}{|c|}{ Categorical class variables } \\
\hline \multirow{15}{*}{ Information source } & \multirow{3}{*}{ Nobody } & 1 & 255.23 & \multirow{3}{*}{96.419} & \multirow{3}{*}{$<.001$} & \multirow{3}{*}{$1-2,2-3$} \\
\hline & & 2 & 367.98 & & & \\
\hline & & 3 & 249.34 & & & \\
\hline & \multirow{3}{*}{ Supervisor } & 1 & 329.74 & \multirow{3}{*}{80.785} & \multirow{3}{*}{$<.001$} & \multirow{3}{*}{$1-2,1-3,2-3$} \\
\hline & & 2 & 240.62 & & & \\
\hline & & 3 & 371.24 & & & \\
\hline & \multirow{3}{*}{ Family } & 1 & 331.99 & \multirow{3}{*}{68.511} & \multirow{3}{*}{$<.001$} & \multirow{3}{*}{$1-2,2-3$} \\
\hline & & 2 & 246.28 & & & \\
\hline & & 3 & 337.62 & & & \\
\hline & \multirow{3}{*}{ Peers } & 1 & 309.82 & \multirow{3}{*}{28.392} & \multirow{3}{*}{$<.001$} & \multirow{3}{*}{$1-2,2-3$} \\
\hline & & 2 & 279.20 & & & \\
\hline & & 3 & 310.57 & & & \\
\hline & \multirow{3}{*}{ Others } & 1 & 316.22 & \multirow{3}{*}{12.618} & \multirow{3}{*}{.002} & \multirow{3}{*}{$1-2,2-3$} \\
\hline & & 2 & 273.87 & & & \\
\hline & & 3 & 311.42 & & & \\
\hline \multirow{11}{*}{ Working methods } & \multirow{3}{*}{ Nobody } & 1 & 242.04 & \multirow{3}{*}{282.172} & \multirow{3}{*}{$<.001$} & \multirow{3}{*}{$1-2,1-3,2-3$} \\
\hline & & 2 & 410.91 & & & \\
\hline & & 3 & 176.05 & & & \\
\hline & \multirow{3}{*}{ Supervisor } & 1 & 329.63 & \multirow{3}{*}{196.137} & \multirow{3}{*}{$<.001$} & \multirow{3}{*}{$1-2,1-3,2-3$} \\
\hline & & 2 & 204.77 & & & \\
\hline & & 3 & 409.86 & & & \\
\hline & & 1 & 331.79 & & & \\
\hline & Family & 2 & 238.28 & 101.236 & $<.001$ & $1-2,2-3$ \\
\hline & & 3 & 351.22 & & & \\
\hline & Peers & 1 & 313.76 & 49053 & $<001$ & $1-2,2-3$ \\
\hline & 100 & 2 & 270.58 & & & \\
\hline
\end{tabular}




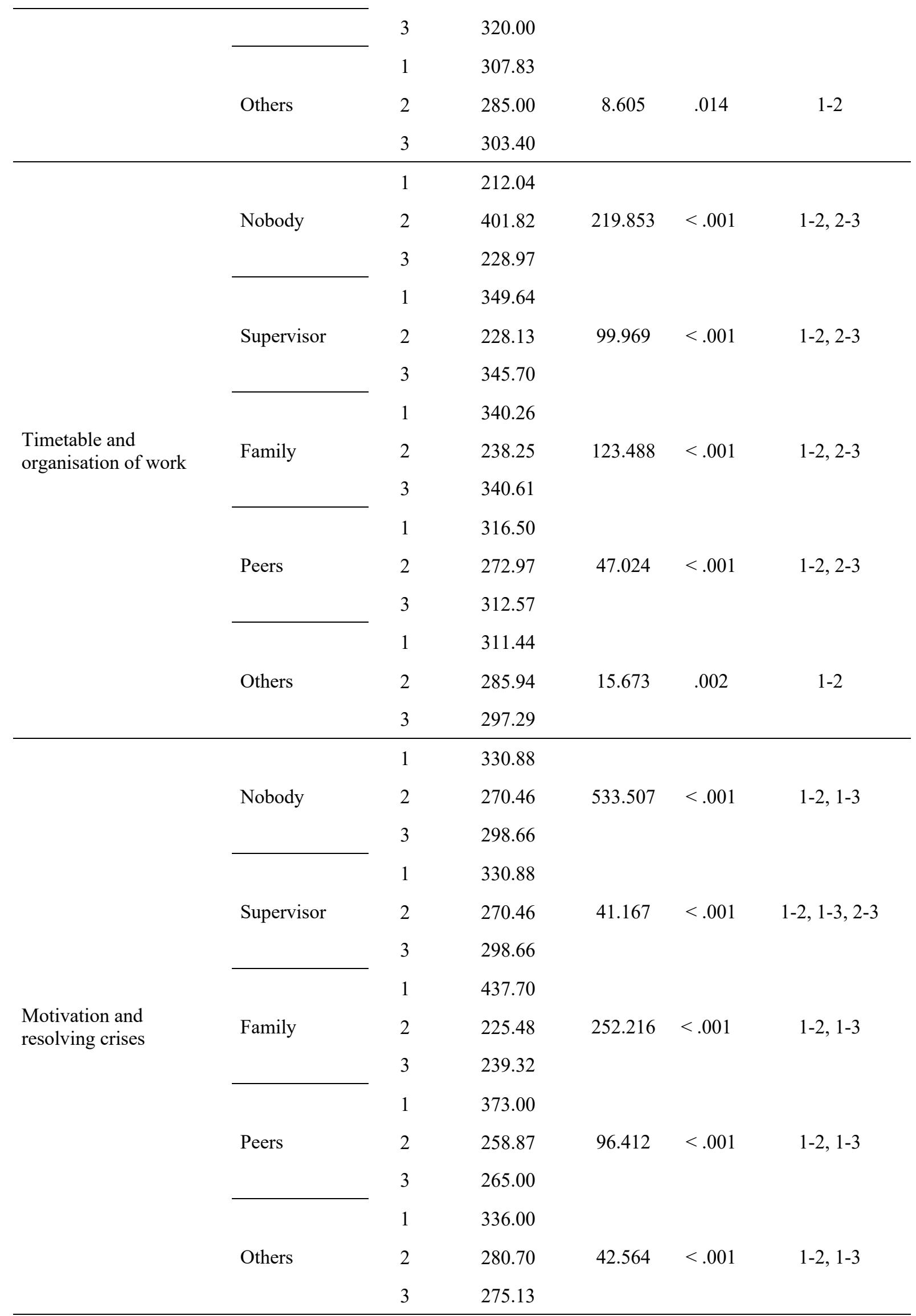


Hirt et al

\begin{tabular}{|c|c|c|c|c|c|c|}
\hline \multicolumn{7}{|l|}{ Metric class variables } \\
\hline \multirow{3}{*}{ Perceived need for help } & & 1 & 240.74 & \multirow{3}{*}{26.040} & \multirow{3}{*}{$<.001$} & \multirow{3}{*}{$1-2,1-3,2-3$} \\
\hline & & 2 & 349.16 & & & \\
\hline & & 3 & 285.73 & & & \\
\hline \multirow{9}{*}{$\begin{array}{l}\text { Perceived frequency of } \\
\text { asking for help }\end{array}$} & \multirow{3}{*}{ Supervisor } & 1 & 275.65 & \multirow{3}{*}{63.447} & \multirow{3}{*}{$<.001$} & \multirow{3}{*}{$1-2,2-3$} \\
\hline & & 2 & 338.35 & & & \\
\hline & & 3 & 262.41 & & & \\
\hline & \multirow{3}{*}{ Family } & 1 & 224.42 & \multirow{3}{*}{29.881} & \multirow{3}{*}{$<.001$} & \multirow{3}{*}{$1-2,1-3,2-3$} \\
\hline & & 2 & 352.31 & & & \\
\hline & & 3 & 298.60 & & & \\
\hline & \multirow{3}{*}{ Peers } & 1 & 243.35 & \multirow{3}{*}{48.847} & \multirow{3}{*}{$<.001$} & \multirow{3}{*}{$1-2,2-3$} \\
\hline & & 2 & 325.86 & & & \\
\hline & & 3 & 273.06 & & & \\
\hline
\end{tabular}

Note. $\chi^{2}=$ chi-square $(d f=2)$.

The second class (see Figure 2) formed the largest group in the implementation stage with $42.9 \%$ of the students $(n=259)$. It seemed to be highly similar to the third class from the first stage. Figure 2 shows that the second class had by far the highest levels of self-reported perceived need for help $(M=$ $3.66, S D=1.02)$ and perceived frequency of asking for help from the supervisor $(M=4.04, S D=1.02)$, family $(M=3.94, S D=1.44)$ and peers $(M=2.55, S D=1.27)$ compared to the other two classes at this stage. A closer examination of the issue areas in combination with the contact persons (see Table 7) apparently indicated that the students in the second class primarily turned to the supervisor for factrelated issue areas (information source, working methods, timetable and organisation of work). However, they seemed to prefer to ask the family for help in overcoming crises (motivation and resolving crises). We named this class factual supervisor-focused and motivational family-focused.

The third class $(25.2 \%, \mathrm{n}=152)$ constituted the smallest class (see Figure 2). Here, the students showed an average value of $M=3.25(S D=1.02)$ for self-reported need for help and therefore were in the medium range. The perceived frequency of help seeking was also in the medium range (family, $M$ $=3.44, S D=1.43$; peers, $M=2.18, S D=1.27$ ), except for perceived frequency of asking the supervisor, which was the lowest in comparison $(M=3.56, S D=1.02)$. This class also stated that they had not turned to anyone except for help on motivational issue areas (motivation and resolving crises, see Table 7). According to the students, the family was consulted in such cases. This rationale underlies the naming of this class as motivational family-focused. 


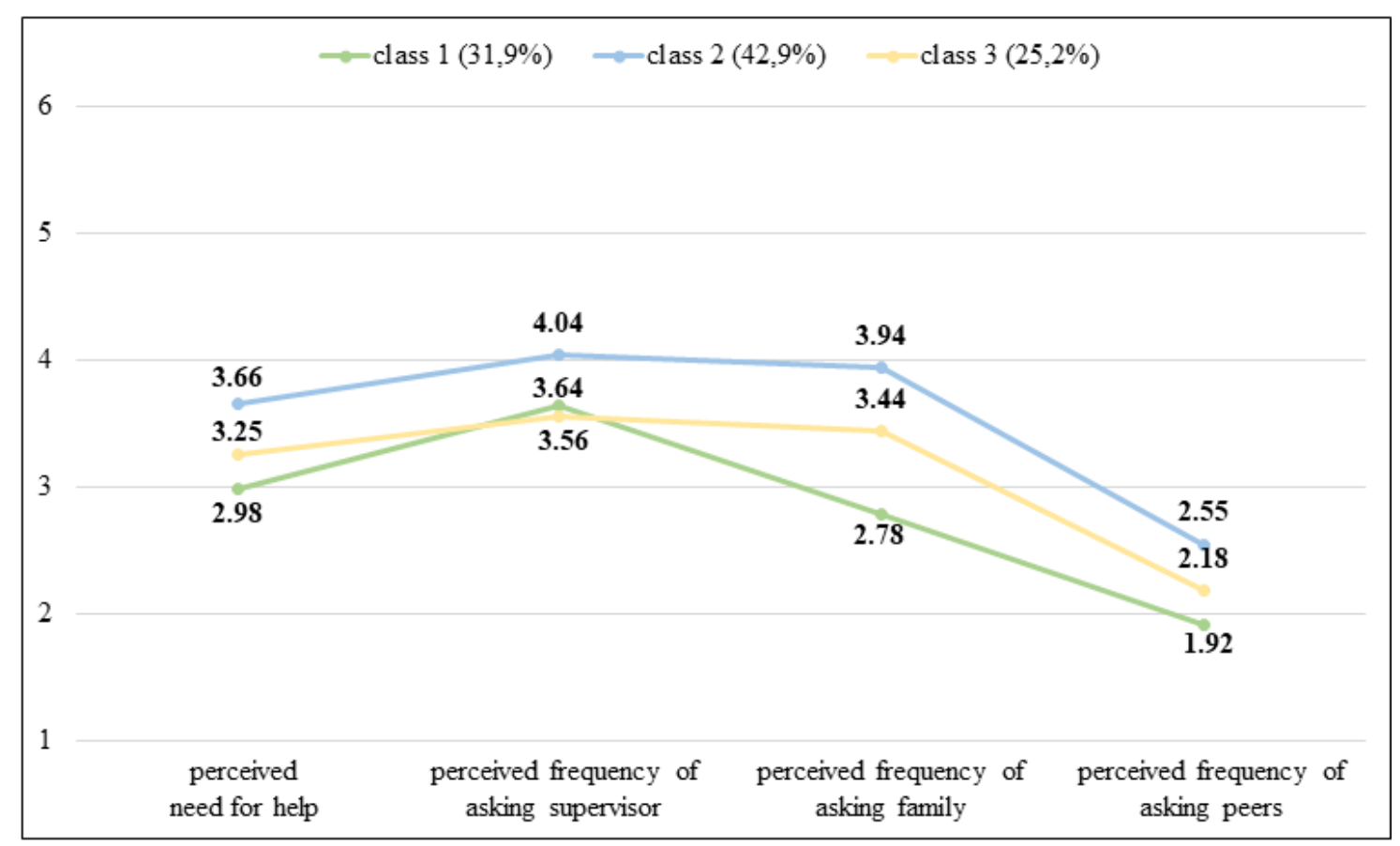

Figure 2. Mean values of the respective metric class variables of the implementation stage $(\mathrm{t} 2, \mathrm{n}=603)$. Perceived need for help: 1 = not at all reliant on help, $6=$ entirely reliant on help. Perceived frequency of asking: 1 = never, 6 = very often. Class $1=$ independents, Class 2 = factual supervisor-focused and motivational family-focused, Class 3 = motivational family-focused. 
Table 7

Probabilities for the Respective Categorical Class Variables in the Implementation Stage (t2)

\begin{tabular}{|c|c|c|c|c|}
\hline \multirow[t]{2}{*}{$\mathrm{n}=551$} & & \multicolumn{3}{|c|}{ Probability of selecting response option } \\
\hline & & Class $1(31.9 \%)$ & Class $2(42.9 \%)$ & Class $3(25.2 \%)$ \\
\hline \multirow{5}{*}{ Information source } & Nobody & 0.482 & 0.086 & 0.524 \\
\hline & Supervisor & 0.340 & 0.642 & 0.229 \\
\hline & Family & 0.129 & 0.419 & 0.120 \\
\hline & Peers & 0.017 & 0.117 & 0.012 \\
\hline & Others & 0.240 & 0.386 & 0.256 \\
\hline \multirow{5}{*}{ Working methods } & Nobody & 0.611 & 0.043 & 0.823 \\
\hline & Supervisor & 0.334 & 0.748 & 0.075 \\
\hline & Family & 0.100 & 0.417 & 0.045 \\
\hline & Peers & 0.019 & 0.166 & 0.001 \\
\hline & Others & 0.060 & 0.138 & 0.064 \\
\hline \multirow{5}{*}{$\begin{array}{l}\text { Timetable and organisation } \\
\text { of work }\end{array}$} & Nobody & 0.779 & 0.147 & 0.722 \\
\hline & Supervisor & 0.204 & 0.614 & 0.213 \\
\hline & Family & 0.022 & 0.359 & 0.022 \\
\hline & Peers & 0.000 & 0.146 & 0.011 \\
\hline & Others & 0.005 & 0.088 & 0.057 \\
\hline \multirow{5}{*}{ Motivation and resolving crises } & Nobody & 1.000 & 0.062 & 0.000 \\
\hline & Supervisor & 0.011 & 0.214 & 0.116 \\
\hline & Family & 0.024 & 0.737 & 0.679 \\
\hline & Peers & 0.000 & 0.381 & 0.367 \\
\hline & Others & 0.000 & 0.187 & 0.202 \\
\hline
\end{tabular}

Note. Class 1 = independents; Class 2 = motivational family-focused; Class 3 = factual supervisor-focused and motivational family-focused; in bold $=$ probabilities with a value $>0.500$.

\subsubsection{Social help-seeking types in the final stage ( $t 3)$}

We also found three classes in the last stage of the creation process (about one month before the submission of the paper). The differences between classes in the final stage are presented in Table 8. Figure 3 includes the mean values of the metric class variables for the three latent classes and Table 9 presents the respective probabilities for the categorical class variables. 
Table 8

Differences Between Classes in the Final Stage (t3)

\begin{tabular}{|c|c|c|c|c|c|c|}
\hline \multicolumn{2}{|l|}{$\mathrm{n}=559$} & Class & Mean rank & $\chi^{2}$ & $p$ & Class differences \\
\hline \multicolumn{7}{|c|}{ Categorical class variables } \\
\hline \multirow{15}{*}{ Information source } & \multirow{3}{*}{ Nobody } & 1 & 258.24 & \multirow{3}{*}{29.273} & \multirow{3}{*}{$<.001$} & \multirow{3}{*}{$1-2,1-3,2-3$} \\
\hline & & 2 & 295.44 & & & \\
\hline & & 3 & 343.41 & & & \\
\hline & \multirow{3}{*}{ Supervisor } & 1 & 333.11 & \multirow{3}{*}{36.300} & \multirow{3}{*}{$<.001$} & \multirow{3}{*}{$1-2,2-3$} \\
\hline & & 2 & 313.96 & & & \\
\hline & & 3 & 252.27 & & & \\
\hline & \multirow{3}{*}{ Family } & 1 & 334.42 & \multirow{3}{*}{36.384} & \multirow{3}{*}{$<.001$} & \multirow{9}{*}{$1-2,2-3$} \\
\hline & & 2 & 307.78 & & & \\
\hline & & 3 & 259.04 & & & \\
\hline & \multirow{3}{*}{ Peers } & 1 & 302.32 & \multirow{3}{*}{0.479} & \multirow{3}{*}{.787} & \\
\hline & & 2 & 300.41 & & & \\
\hline & & 3 & 297.38 & & & \\
\hline & \multirow{3}{*}{ Others } & 1 & 307.83 & \multirow{3}{*}{1.175} & \multirow{3}{*}{.556} & \\
\hline & & 2 & 299.12 & & & \\
\hline & & 3 & 294.09 & & & \\
\hline \multirow{15}{*}{ Working methods } & \multirow{3}{*}{ Nobody } & 1 & 232.57 & \multirow{3}{*}{119.570} & \multirow{3}{*}{$<.001$} & \multirow{3}{*}{$1-2,1-3,2-3$} \\
\hline & & 2 & 272.50 & & & \\
\hline & & 3 & 396.02 & & & \\
\hline & \multirow{3}{*}{ Supervisor } & 1 & 337.51 & \multirow{3}{*}{47.313} & \multirow{3}{*}{$<.001$} & \multirow{3}{*}{$1-3,2-3$} \\
\hline & & 2 & 314.62 & & & \\
\hline & & 3 & 247.46 & & & \\
\hline & & 1 & 335.33 & & & \\
\hline & Family & 2 & 324.45 & 69.492 & $<.001$ & $1-3,2-3$ \\
\hline & & 3 & 236.77 & & & \\
\hline & & 1 & 324.91 & & & \\
\hline & Peers & 2 & 293.63 & 17.796 & $<.001$ & $1-2,1-3$ \\
\hline & & 3 & 285.80 & & & \\
\hline & & 1 & 311.09 & & & \\
\hline & Others & 2 & 302.46 & 8.424 & .015 & $1-3$ \\
\hline & & 3 & 286.86 & & & \\
\hline
\end{tabular}


Hirt et al

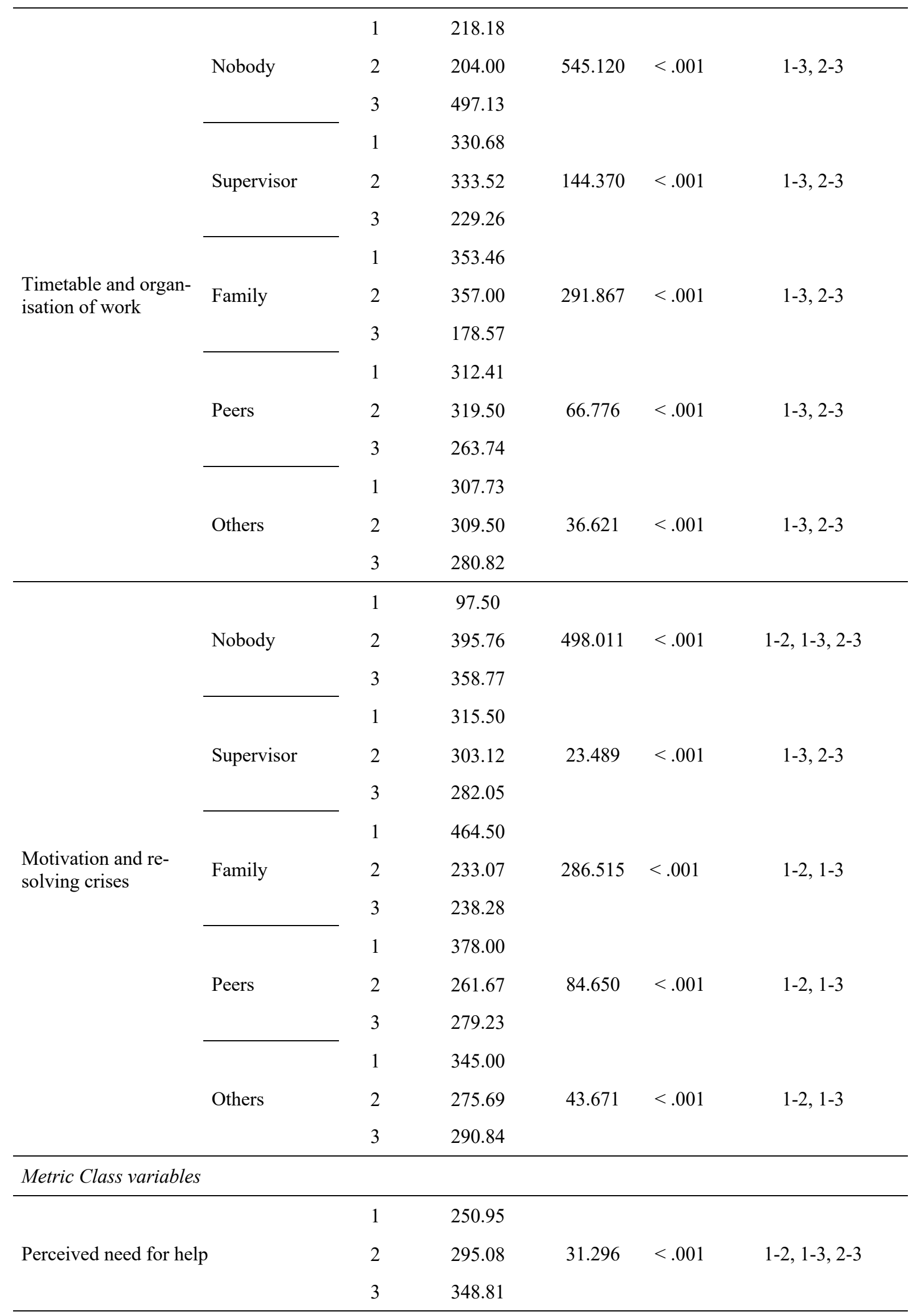




\begin{tabular}{|c|c|c|c|c|c|c|}
\hline \multirow{9}{*}{$\begin{array}{l}\text { Perceived frequency } \\
\text { of asking for help }\end{array}$} & \multirow{3}{*}{ Supervisor } & 1 & 276.82 & \multirow{3}{*}{19.891} & \multirow{3}{*}{$<.001$} & \multirow{3}{*}{$1-2,2-3$} \\
\hline & & 2 & 290.30 & & & \\
\hline & & 3 & 343.99 & & & \\
\hline & \multirow{3}{*}{ Family } & 1 & 220.46 & \multirow{3}{*}{68.756} & \multirow{3}{*}{$<.001$} & \multirow{3}{*}{$1-2,1-3,2-3$} \\
\hline & & 2 & 302.79 & & & \\
\hline & & 3 & 366.66 & & & \\
\hline & \multirow{3}{*}{ Peers } & 1 & 238.50 & \multirow{3}{*}{31.036} & \multirow{3}{*}{$<.001$} & \multirow{3}{*}{$1-2,1-3$} \\
\hline & & 2 & 321.25 & & & \\
\hline & & 3 & 324.43 & & & \\
\hline
\end{tabular}

Note: $\chi^{2}=$ chi-square $(d f=2)$

An examination of the metric class variables (see Figure 3) revealed that the first class $(28.4 \%$, $\mathrm{n}=171)$ had the lowest mean values compared to the other two classes. The relatively low dependence on help $(M=3.63, S D=1.05)$ indicated by the students also corresponded to perceived frequency of seeking help from other persons (supervisor, $M=3.03, S D=1.27$; family, $M=3.54, S D=1.31$; peers, $M=1.99, S D=1.39$ ). The probabilities regarding the categorical class variables (see Table 9) similarly confirmed this finding, as the students in this class were apparently the most likely not to have asked anyone for help in the issue areas surveyed. Hence, we named the class independents.

The second class $(39.4 \%, \mathrm{n}=238$, see Figure 3 ) had a self-reported need for help of $M=3.98$ $(S D=1.05)$. The perceived frequency of seeking help from the supervisor was $M=3.20(S D=1.27), M$ $=4.27(S D=1.31)$ for the family, and $M=2.69(S D=1.39)$ for the peers (see Figure 3). Based on the metric class variables, these values were middle ranged compared to the other two classes. However, if one considers the probabilities of the categorical variables (see Table 9), the family was clearly asked for help in particular with the issue area of timetable and organisation of work and also when motivational aspects were involved (motivation and resolving crises). The family thus played a central role in this class, and we therefore called it motivational family-focused.

The family was likewise central to the third class $(32.2 \%, \mathrm{n}=194$, see Figure 3$)$, especially in matters of solving problems relating to issues in timetable and organisation of work and overcoming crises (see Table 9). The mean values for the metric class variables (see Figure 3) were the highest compared to the other two classes (perceived need for help, $M=4.30, S D=1.05$; perceived frequency of asking supervisor, $M=3.62, S D=1.27$; perceived frequency of asking family, $M=4.79, S D=1.31$; perceived frequency of asking peers, $M=2.75, S D=1.39)$. Given this family-based orientation, we named this class factual and motivational family-focused. 


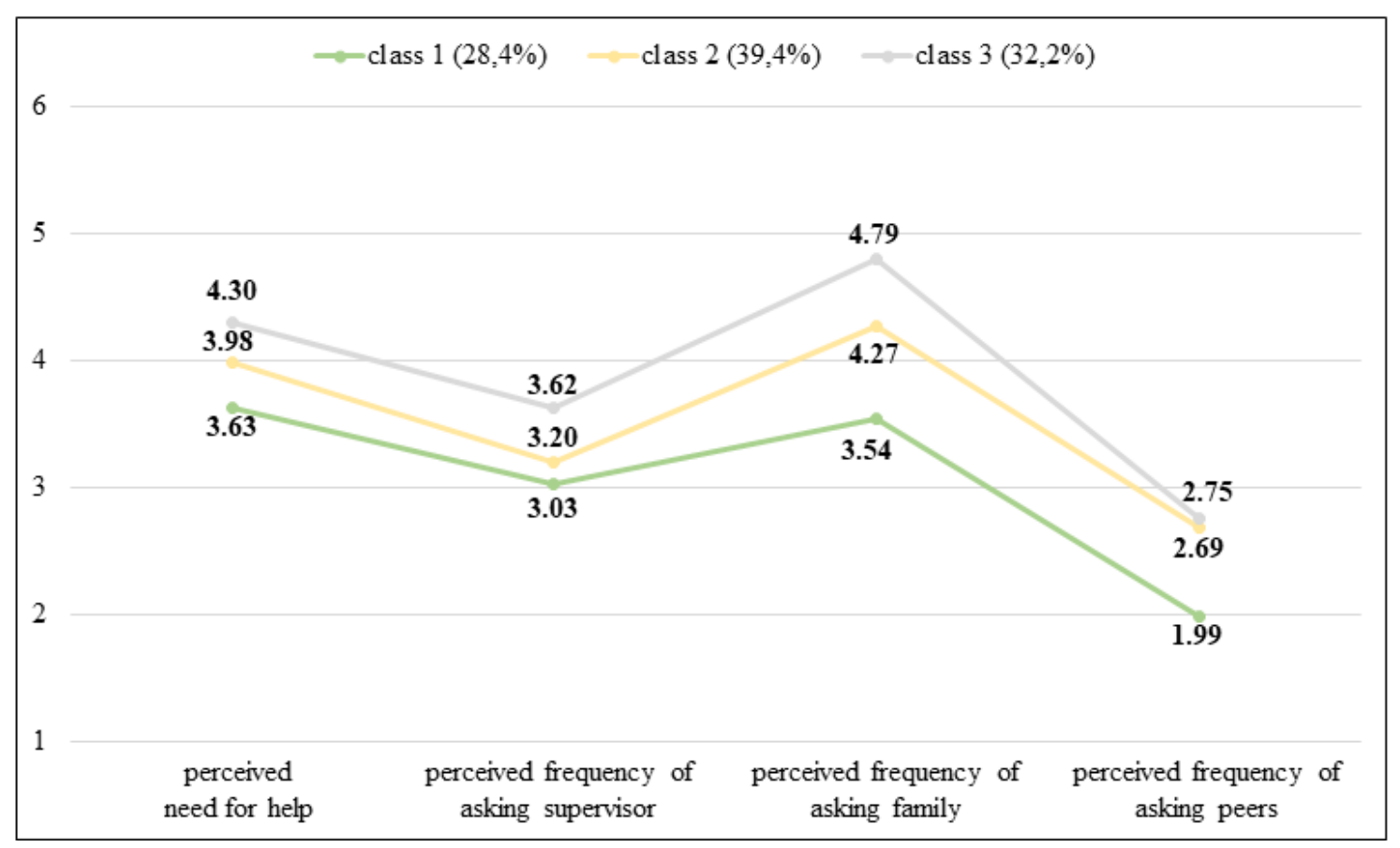

Figure 3. Mean values of the respective metric class variables in the final stage ( $\mathrm{t} 3, \mathrm{n}=603)$. Perceived need for help: $1=$ not at all reliant on help, $6=$ entirely reliant on help. Perceived frequency of asking: $1=$ never, 6 = very often. . Class $1=$ independents, Class $2=$ motivational family-focused, Class $3=$ factual and motivational family-focused. 
Table 9

Probabilities for the Respective Categorical Class Variables of the Final Stage (t3)

\begin{tabular}{|c|c|c|c|c|}
\hline \multirow[t]{2}{*}{$\mathrm{n}=585$} & & \multicolumn{3}{|c|}{ Probability of selecting response option } \\
\hline & & Class $1(28.2 \%)$ & Class $2(30.9 \%)$ & Class $3(40.9 \%)$ \\
\hline \multirow{5}{*}{ Information source } & Nobody & 0.603 & 0.487 & 0.316 \\
\hline & Supervisor & 0.173 & 0.229 & 0.442 \\
\hline & Family & 0.089 & 0.171 & 0.342 \\
\hline & Peers & 0.048 & 0.054 & 0.062 \\
\hline & Others & 0.175 & 0.207 & 0.225 \\
\hline \multirow{5}{*}{ Working methods } & Nobody & 0.716 & 0.594 & 0.170 \\
\hline & Supervisor & 0.130 & 0.197 & 0.435 \\
\hline & Family & 0.112 & 0.141 & 0.443 \\
\hline & Peers & 0.023 & 0.126 & 0.156 \\
\hline & Others & 0.042 & 0.070 & 0.120 \\
\hline \multirow{5}{*}{$\begin{array}{l}\text { Timetable and organisation } \\
\text { of work }\end{array}$} & Nobody & 0.956 & 1.000 & 0.049 \\
\hline & Supervisor & 0.017 & 0.008 & 0.346 \\
\hline & Family & 0.010 & 0.000 & 0.579 \\
\hline & Peers & 0.022 & 0.000 & 0.182 \\
\hline & Others & 0.006 & 0.000 & 0.093 \\
\hline \multirow{5}{*}{ Motivation and resolving crises } & Nobody & 1.000 & 0.005 & 0.129 \\
\hline & Supervisor & 0.000 & 0.037 & 0.115 \\
\hline & Family & 0.000 & 0.769 & 0.756 \\
\hline & Peers & 0.000 & 0.386 & 0.332 \\
\hline & Others & 0.000 & 0.232 & 0.180 \\
\hline
\end{tabular}

Note: Class 1 = independents; Class 2 = motivational family-focused; Class 3 = factual and motivational family-focused; in bold $=$ probabilities with a value $>0.500$.

\subsection{Changes in Social Help-Seeking Types Over Time (LTA)}

Before proceeding to the results of the LTA, several methodological notes need to be provided. The first is that "[if] the same measurement model is used across all time points (e.g., LCA) and the same number and type of classes are used, it is reasonable to explore measurement invariance" (Nylund, 2007 , p. 44). Further, Nylund (2007) notes that a full measurement invariance is not always plausible, depending on which classes have emerged from the LCA. In this investigation, the LCA produced the same number but not the same types of classes over time. One of the three classes seemed to occur at all three measurement points (independents), and two classes transpired in each case at two measurement points (factual supervisor-focused and motivational family-focused, motivational family-focused). Therefore, Model 1 was constructed first, in which the thresholds and intercepts became restricted over time for the same occurring classes. Model 1 was finally compared with a second model (Model 2), in 
which the thresholds and intercepts were freely estimated over time. Due to the large number of cells in the frequency table, the chi-square test could not be computed. A model comparison using the AIC and BIC provides information on the particular model that is more suitable for the available data, whereby the lower values correspond to the better fitting model (Geiser, 2011). As an additional dimension, the entropy, which should have a value greater than .80, was used (Rost, 2006). Finally, the more suitable model was used for interpreting the latent transition probabilities.

Table 10 summarizes the values of the model comparison: Model 1 had no restrictions toward Model 2, which had restrictions for constant classes over time. The model comparison indicated that the two models only differed marginally from each other. As the entropy value for Model 1 was more favourable, this model was used for further analyses. This decision can also be justified theoretically, because although some classes remained the same over time, this does not signify that all persons remained in the same classes.

Table 10

Statistical Fit Indices for the Most Appropriate Model: Comparison of the Freely Estimated Model (Model 1) with the Restricted Model (Model 2)

\begin{tabular}{llll}
\hline Model & BIC & AIC & Entropy \\
\hline Model 1: no restrictions & 55386.773 & 54356.724 & 0.940 \\
Model 2: restrictions for constant classes over timea & 55324.639 & 54717.174 & 0.880 \\
\hline
\end{tabular}

Note. BIC = Bayesian; AIC = Akaike; $\mathrm{a}=$ independents, $\mathrm{t} 1 / 2, \mathrm{t} 2 / 1, \mathrm{t} 3 / 1$; factual supervisor-focused and motivational familyfocused, $\mathrm{t} 1 / 3, \mathrm{t} 2 / 2$; motivational family-focused, $\mathrm{t} 2 / 3, \mathrm{t} 3 / 2$.

Figure 4 shows the latent transition probabilities for the total sample from t 1 to $\mathrm{t} 2$ and from $\mathrm{t} 2$ to $\mathrm{t} 3$. The probabilities of 0.11 and 0.27 ( $\mathrm{t} 1$ to $\mathrm{t} 2$ ), and 0.41 ( $\mathrm{t} 2$ to $\mathrm{t} 3$ ) in bold type indicated a relatively low stability of the intraindividual behavioural style of students in the classes of the same name over time.

First, the probabilities for a change in the SHS type from the concept development stage (t1) to the implementation stage (t2) were considered. Persons who belonged to the factual supervisor-focused class (Class 1) in the concept development stage (t1) switched to independents (Class 1) for the implementation stage ( $\mathrm{t} 2$ ) with a $62 \%$ probability and to the motivational family-focused class (Class 3 ) with a probability of $16 \%$. As the factual supervisor-focused only existed for t1, we cannot speak of permanent members of this group. All these students changed to another SHS group for the implementation stage (t2): $62 \%$ changed to independents, $23 \%$ to factual supervisor-focused and motivational family-focused and 16\% to motivational family-focused. Students who belonged to the independents (Class 2) in the concept development stage (t1) were likely to change to the factual supervisor-focused and motivational family-focused (Class 2) for the implementation stage (t2) with a $66 \%$ probability and to the motivational family-focused (Class 3 ) with a probability of $13 \%$. However, approximately $11 \%$ remained in the class of independents. Persons who belonged to the class factual supervisor-focused and motivational family-focused (Class 3) switched to independents (Class 1) for the implementation stage ( $\mathrm{t} 2$ ) with a probability of $28 \%$ and to the class motivational family-focused (Class 3 ) with a probability of $45 \%$. About $27 \%$ remained in the class factual supervisor-focused and motivational family-focused (Class 2).

Second, we examined the probabilities of changing the SHS type from the implementation stage ( $\mathrm{t} 2$ ) to the final stage ( $\mathrm{t} 3$ ). Students in the class independents (Class 1 ) had a probability of $41 \%$ of remaining in this class for the final stage, and they did not change to motivational family-focused (Class 2). However, they were 59\% likely to switch to factual and motivational family-focused (Class 3). Persons who belonged to the factual supervisor-focused and motivational family-focused (Class 2) in the implementation stage (t2) did not switch to independents (Class 1), but they were $46 \%$ likely to 
join the motivational family-focused (Class 2) in the final stage. Nevertheless, $54 \%$ moved to the factual and motivational family-focused (Class 3). Persons belonging to $t 2$ in the class of motivational family-focused (Class 3) neither switched to independents nor stayed in the same class in the final stage. A full $100 \%$ of this Class 3 changed to factual and motivational family-focused for the final stage (t3).

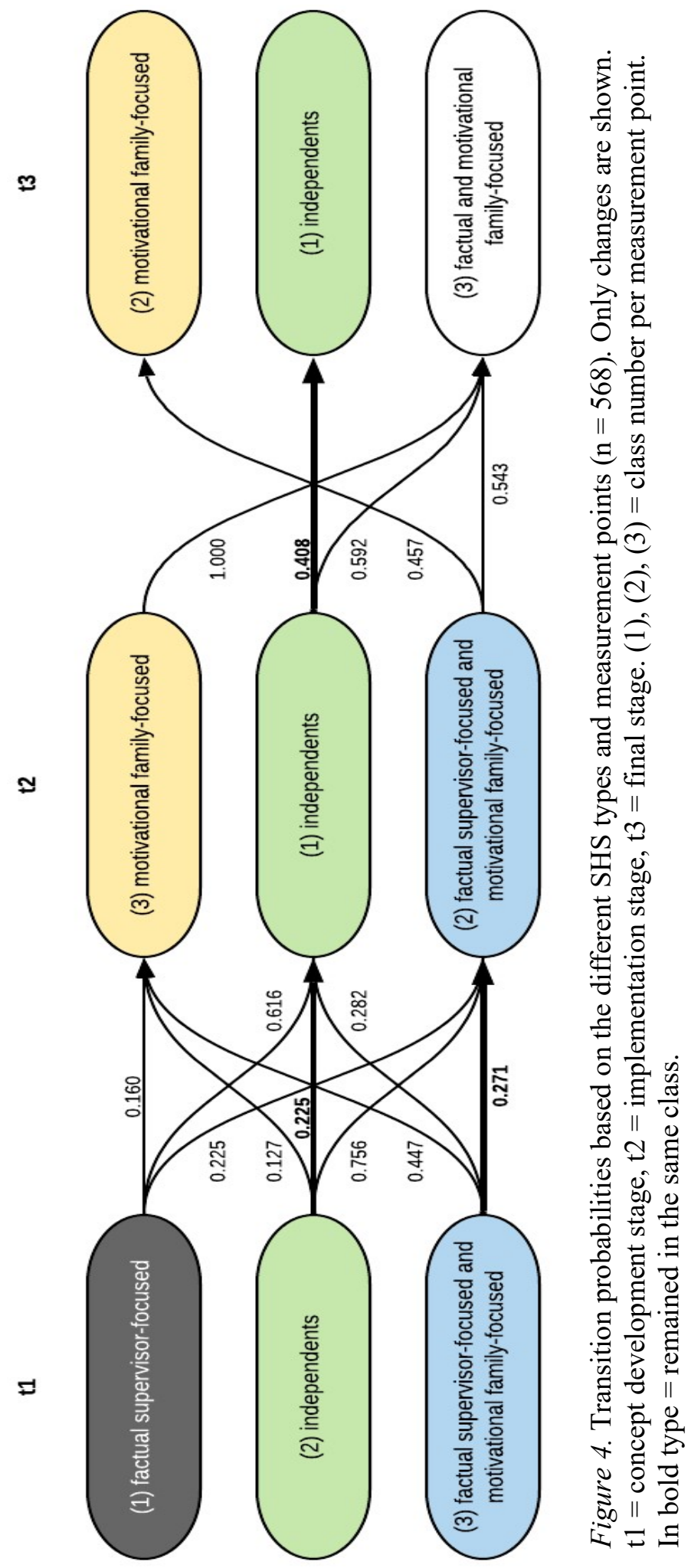


Hirt et al

\subsection{Disparities Between the Social Help-Seeking Types per Stage Regarding Academic Achieve-} ment

To answer the third question, a Kruskal-Wallis $\mathrm{H}$ test was run to determine any differences in grades between the three SHS types per stage and therefore ascertain whether the SHS type to which the students belonged per stage played a role in academic performance. The distributions of grades were similar for all SHS types in all three stages, as assessed by the visual inspection of the box plots. The results indicated that the median values did not differ statistically significantly between the SHS types in the concept development stage (t1), $\chi^{2}(2)=2.20, \mathrm{p}=.333$, or in the implementation stage (t2), $\chi^{2}(2)$ $=1.36, \mathrm{p}=.506$, or in the final stage ( $\mathrm{t} 3), \chi 2(2)=0.54, \mathrm{p}=.763$ (see Table 11).

Table 11

Disparities Between SHS types per Stage Regarding Academic Achievement

\begin{tabular}{cccccccc}
\hline $\mathrm{t}$ & SHS Type & $n$ & Mdn & Mean rank & $\chi^{2}$ & $d f$ & $p$ \\
\hline \multirow{3}{*}{$\mathrm{t} 1$} & 1 & 114 & 5.50 & 269.12 & & & \\
& 2 & 180 & 5.50 & 294.26 & 2.20 & 2 & .333 \\
& 3 & 266 & 5.50 & 276.06 & & & \\
\hline \multirow{2}{*}{$\mathrm{t} 2$} & 1 & 181 & 5.50 & 291.52 & & & \\
& 2 & 238 & 5.50 & 276.49 & 1.36 & 2 & .506 \\
& 3 & 141 & 5.50 & 273.11 & & & \\
\hline \multirow{2}{*}{$\mathrm{t} 3$} & 1 & 160 & 5.50 & 281.38 & & & \\
& 2 & 226 & 5.50 & 285.18 & 0.54 & 2 & .763 \\
& 3 & 174 & 5.32 & 273.62 & & & \\
\hline
\end{tabular}

Note. $\mathrm{t}=$ measurement point; $\mathrm{n}=$ number of cases; $M d n=$ median $(1$ to 6$) ; \chi^{2}=$ chi-square; $d f=$ degrees of freedom; $p=$ level of significance (asymptotic, two-sided). No multiple comparisons due to non-significant differences between samples in the overall test.

\section{Discussion}

\subsection{Overall Results}

The main objectives of this study were to adopt a person-centred approach to gain in-depth insights into how young adults seek help in dealing with a real, challenging long-term task; to attempt to break it down into specific types of SHS strategies in view of the need for help, different issue areas and various contact persons; and to integrate the role of academic achievement. Swiss students at different grammar schools at the upper secondary level participated in the study and thus provided us with insights into their help-seeking behaviour.

The aim of this study was threefold. The first aim was to ascertain the existence of different SHS types in each task stage of creating an academic paper outside the classroom context (Q1). The SHS process is characterized by many different decision-making options (Nelson-Le Gall, 1981). In addition, SHS is dependent on various characteristics of the person giving help (e.g. Ryan \& Shim, 2012). Based on these points and the diverse challenges that the learners encounter in each creation phase, we expected to find different SHS types in each stage of the long-term task under investigation (hypothesis 1). This hypothesis can be confirmed: Not every stage includes all the same SHS types. The LCAs per stage indicate that one of the three classes occurs in all stages of the paper creation process, 
namely, independents. This group is referred to as avoiders in Karabenick (2003) because of their low values in terms of the quantity of SHS. However, we chose to call them independents instead, because in addition to the low perceived frequency of asking for help, they also report less perceived need for help. The members of this class could be students who already have some previous knowledge and therefore encounter fewer challenges. This low perceived need for help and the associated low perceived frequency of asking for help confirm the results of Karabenick and Knapp $(1988,1991)$, in which students with a very low need are the least likely to seek help. The extent to which this case is due to competencies in self-regulated learning (Karabenick \& Knapp, 1991) would require further examination. Students who are factual supervisor-focused and motivational family-focused only appear in the first two stages. These group members seem to be highly uncertain about what to exactly do. Furthermore, they do not seem to know for sure how to motivate themselves in the concept development and the implementation stage, based on their comparatively highest values for both stages regarding perceived need and perceived frequency of seeking help from the supervisor concerning factual issues and from the family regarding motivational issues. However, the underlying reasons for these generally increased values would have to be verified in further investigations. In contrast, the motivational familyfocused group only appears in the last two stages, which makes sense, as maintaining motivation and persisting is especially relevant for long-term tasks, and challenges in this regard might arise more toward the middle and the end of the process (Ulmi, Bürki, Verhein \& Marti, 2017). Research has also revealed that motivational aspects are preferably discussed with trusted persons (Boldero \& Fallon, 1995; Fallon \& Bowles, 1999; Nelson Le Gall, Gumerman \& Scott-Jones, 1983). Factual supervisorfocused students only appeared in the concept development stage. Motivational challenges do not seem to be an issue for this group. In addition, the factual and motivational family-focused appear in only one of the stages, namely, the final stage. These students mainly report asking the family for help with motivational issues and issues in work organisation. However, a striking aspect of the final stage is that none of the class members has a strong orientation toward supervisors. Work on the paper should have further progressed by this time; hence, the inhibition threshold for asking the supervisor might naturally rise, as the supervisor is also the assessor (Bonati \& Hadorn, 2009). Another possibility is that the ensuing questions no longer concern the area of competence or responsibility of the supervisor, such as proofreading the work. Overall, the supervisors do not seem to be perceived as the contact persons with whom crises or motivational challenges can be discussed. This inference particularly confirms the findings of Boldero and Fallon (1995), who highlighted that personal issues are most likely to be discussed with family or peers. Thus, compared to Karabenick's types (2003), we have found a hybrid type in which informal and formal sources are asked for help, namely, the factual supervisor-focused and motivational family-focused. This type appears because we focused on the specific issue areas for certain contact persons, which in turn underlines the relevance of this differentiated perspective.

The second aim was to determine the extent to which these SHS types change during the course of the creation process of a long-term task (Q2). In accordance with Zimmerman (2002), we postulated that experiences in one stage can induce a change in self-reported behaviour in the subsequent stage. Additionally, different problems can arise in long-term tasks, which in turn can have an influence on SHS. We consequently assumed that the students can switch between the SHS types and that these types do not have to be stable over time (hypothesis 2), as was expected by Finney et al. (2018). This hypothesis can be confirmed, as the LTA indicates a diligent switching between SHS types over time. Whether these changes are due to adaptive SHS processes or to different key activities within the three stages requires further investigation. Regarding the transfer between types, the explorative assumption was made that students who receive help from their supervisor that they find useful in the first stage need less help later on (hypothesis 3 ). Sixty-two percent of the factual supervisor-focused students (t1) change to the class of independents (t2). Thus, hypothesis 3 can be largely confirmed. It indicates that these students feel that they are prepared to implement the paper concept based on a productive concept stage with the supervisor. An effective concept and precise aim specifications facilitate targeted work afterwards (McCardle, Webster, Haffey \& Hadwin, 2017; Ritschl, Weigl \& Stamm, 2016), which in turn benefits independent work. Thus, we also assumed that without a broad discussion on or clarification of the concept, the students might need help at a later stage (hypothesis 4). Seventy-six percent of students 
from the independents (t1) changed to the factual supervisor-focused and motivational family-focused (t2) type of SHS, confirming hypothesis 4 . These students seem to have many open factual issues and apparently need help with motivational issues in the implementation stage. The assumption is that the concept was not specifically thought through or that certain questions will only arise during the implementation stage. Questions that are not clarified at the concept development stage can reappear in the implementation stage. Another reason could be a relatively large amount of prior knowledge, which can result in the perceived need for help at the concept development stage (t1) being underestimated by overestimating the understanding of the learning material (Scardamalia \& Bereiter, 1992). We also expected students who need help throughout all the phases with different issues and therefore ask different contact persons for help (hypothesis 5). Students assigned to the motivational family-focused during the implementation stage switch $100 \%$ to the factual and motivational family-focused for the final stage. This large group of students is apparently dependent on help from their families not only with motivational issues but also with factual issues, especially timetable and organisation of the work. Hence, hypothesis 5 can be partially confirmed. Although these students continuously seek help, the contact persons do not vary considerably: These students strongly involve their families to resolve challenges. However, a conclusion that can be derived based on the results is that issues with content simply no longer exist and that these queries must have been resolved with the supervisor beforehand. This group does not turn to the supervisor during either the implementation stage or the final stage; thus, a performance goal orientation should also be considered, as these students may not intend to embarrass themselves in front of their assessing supervisor (Karabenick, 2003; Ryan et al., 2001).

The third aim of the present research was to examine the extent to which the SHS types found per stage are important for academic achievement (Q3). Against the background of previous studies (Butler, 1998, 2006; Finney et al., 2018; Karabenick, 2003; Karabenick \& Knapp, 1988, 1991; Nadler, 1998; Nelson-Le Gall, 1981; Ryan et al., 2005), we had assumed that the SHS types differ in their academic performance (hypothesis 6). This hypothesis could not be confirmed, because no significant differences between the SHS types per stage can be identified. The students examined here were apparently able to adequately assess their need for help and then seek and receive help in such a way that they received a favourable grade on the paper. However, it is another question whether this help-seeking behaviour enhances the student's understanding in the area for which help was sought. This condition would require closer examination of individual help-seeking/help-giving interactions and behaviour and knowledge in future, similar situations.

\subsection{Conclusion for Theory and Practice}

It should be noted for SHS theory that SHS types can significantly change during task stages and thus within a learning process as well. We have found some SHS types that are addressed by the types discovered in previous investigations. Nevertheless, through the identification of the thematic focus of SHS, other SHS types emerge, such as factual supervisor-focused and motivational family-focused. This inference denotes that future investigations should pay more attention to HS as an issuespecific process. Furthermore, SHS avoidance should not be stated unless the need for help has also been considered. This group of students could be quickly misunderstood and mistakenly classified as a 'risk group'. Therefore, SHS types should be interpreted with caution because they may also substantially change depending on the context.

In the context of preparing an academic paper, the students apparently rarely turn to their paper supervisors for help with motivational issues. Nevertheless, paper supervisors in particular could teach suitable motivational regulatory strategies to encourage their students to continue their work (Dignath $\&$ Büttner, 2008). In this case, the supervisors must first be aware that their students are struggling with motivational difficulties. Social interactions concerning not only content but also motivational issues should be intensified (Wolters, 2003). However, this process requires a strong basis of trust between supervisor and student, a relationship that would also allow students to reveal their weaknesses or diffi- 
culties (Butler \& Neuman, 1995; Newman, 2000; Ryan \& Pintrich, 1997). In addition, 62\% of the students who were in the factual supervisor-focused group at the concept development stage switched to the independents. This result illustrates the relevance of close support during the development of the concept for independent work during the implementation stage, which is also described in the coaching literature (e.g. Ulmi et al., 2017).

Most of the students in this study seem to know how to achieve desired grades through helpseeking processes if they have a perceived need for help. Nonetheless, for the help-givers, this help should be provided in a way that enables students to help themselves in similar situations (e.g. by developing appropriate motivational regulation strategies). In other words, helpers such as parents, peers and supervisors should not primarily focus on the students' good grades but should instead direct their support toward sustainability and lifelong learning (EU Council, 2002).

\subsection{Limitations and suggestions for further research directions}

In this study, we adopted a longitudinal, person-centred perspective on SHS types outside the classroom context and integrated important aspects such as perceived need for help, specific issue areas, and the related sources of help. We could therefore show that SHS types can vary based on the different issue areas encountered. However, the data evaluated in this study are based on self-reports regarding SHS. Measurements that are more objective could probably provide deeper and/or extended insights into the SHS processes. This aspect especially relates to measurement of the frequency of seeking help. Notably, our response options reflected the individually perceived frequency of help seeking and not objective frequency. The same applies to assessing the need for help. These aspects should be considered in future studies. Although the recorded academic achievements were not based on self-reports, the students showed a relatively high average grade, which may have caused insignificant differences between the SHS types.

A comparison of extreme groups and the resulting SHS types could lead to extended results. The backgrounds of the individual class members must also be further analysed to improve the understanding of the SHS strategies of the students in these classes; the reason is that individual characteristics such as gender (e.g. Nadler, 1998) and goal orientation (e.g. Butler, 2006; Ryan et al., 2001) can affect SHS behaviour. The influence of the parents' support on the SHS types is an important aspect that is lacking in research up to now. As Newman (2000) was able to confirm that experiences from the parental home can influence help seeking, this area should also be integrated into further analyses of the SHS types.

Finally, how different types of SHS can influence performance levels, as well as how performance is influenced by switching between classes, should be taken into consideration. The outcomes clearly indicate that without the inclusion of analyses relating to family relationships and the cooperation/relationship between the students and the paper supervisor, only vague assumptions can be made about the reasons for the changes. This factor must be taken into account in further analyses. The present analyses are related to the context of producing a compulsory school leaving certificate paper (Matura thesis) at the end of the upper secondary school. Further analyses in the same or a similar context would be needed to strengthen these results, which could particularly show that SHS should be considered context-specifically. 


\section{Keypoints}

- Students who do not seek help are not necessarily social help-seeking (SHS) avoiders, but can also be students who work independently (i.e. students who do not perceive a need for help).

- Within a long-term challenging task with various key activities, students can switch between SHS types.

- For the final grade, the SHS type per task stage is unimportant in this context.

\section{References}

Aleven, V., Stahl, E., Schworm, S., Fischer, F., \& Wallace, R. (2003). Help seeking and help design in interactive learning environments. Review of Educational Research, 73, 277-320. https://doi.org/10.3102/00346543073003277

Asparouhov, T., \& Muthén, B. O. (2014). Variable-specific entropy contribution. Retrieved from https://www.statmodel.com/download/UnivariateEntropy.pdf

Backhaus, N., \& Tuor, R. (2008). Leitfaden für wissenschaftliches Arbeiten, 7. überarbeitete und ergänzte Auflage [Guidelines for scientific work, 7th revised and supplemented edition]. Zurich, Switzerland: Department of Geography, University of Zurich. https://doi.org/10.5167/uzh10134

Boldero, J., \& Fallon, B. J. (1995). Adolescent help seeking: What do they get help for and from whom? Journal of Adolescence, 18, 193-209. https://doi.org/10.1006/jado.1995.1013

Bonati, P., \& Hadorn, R. (2009). Matura- und andere selbständige Arbeiten betreuen. Ein Handbuch für Lehrpersonen und Dozierende. 2., überarbeitete und erweiterte Auflage [Supervising Matura and other independent work. A manual for teachers and lecturers. 2nd, revised and extended edition]. Bern, Switzerland: Hep Verlag.

Butler, R. (1998). Determinants of help seeking: Relations between perceived reasons for classroom help-avoiding and help-seeking behaviors in an experimental context. Journal of Educational Psychology, 90(4), 630-644. https://doi.org/10.1037/0022-0663.90.4.630

Butler, R. (2006). An achievement goal perspective on student help seeking and teacher help giving in the classroom: Theory, research, and educational implications. In S. A. Karabenick \& R. S. Newman (Eds.), Help seeking in academic settings: Goals, groups, and contexts (pp. 17-34). New York, NY: Erlbaum.

Butler, R., \& Neuman, O. (1995). Effects of task and ego achievement goals on help-seeking behaviors and attitudes. Journal of Educational Psychology, 87, 261-271. https://doi.org/10.1037/0022-0663.87.2.261

Dignath, C., \& Büttner, G. (2008). Components of fostering self-regulated learning among students: A meta-analysis on intervention studies at primary and secondary school level. Metacognition Learning, 3, 231-264. https://doi.org/10.1007/s11409-008-9029-x

Elliot, A. J., \& Church, M. A. (1997). A hierarchical model of approach and avoidance achievement motivation. Journal of Personality and Social Psychology, 72(1), 218-232. https://doi.org/10.1037/0022-3514.72.1.218

Elliot, A. J., \& McGregor, H. A. (2001). A 2 x 2 achievement goal framework. Journal of Personality and Social Psychology, 80, 501-519. https://doi.org/10.1037/0022-3514.80.3.501 
Ellis, S. (1997). Strategy choice in sociocultural context. Developmental Review, 17, 490-524. https://doi.org/10.1006/drev.1997.0444

EU Council. (2002). Council resolution of 27 June 2002 on lifelong learning. Official Journal of the European Communities, 9. Retrieved from https://op.europa.eu/en/publication-detail/-/publication/0bf0f197-5b35-4a97-9612-19674583cb5b

Fallon, B. J., \& Bowles, T. (1999). Adolescent help-seeking for major and minor problems. Australian Journal of Psychology, 51(1), 12-18. https://doi.org/10.1080/00049539908255329

Finch, H. W., \& Bronk, K. C. (2011). Conducting confirmatory latent class analysis using Mplus. Structural Equation Modeling: A Multidisciplinary Journal, 18(1), 132-151. https://doi.org/10.1080/10705511.2011.532732

Finney, S. J., Barry, C. L., Horst, S. J., \& Johnston, M. M. (2018). Exploring profiles of academic help seeking: A mixture modeling approach. Learning and individual Differences, 61, 158-171. https://doi.org/10.1016/j.lindif.2017.11.011

Geiser, C. (2011). Datenanalyse mit Mplus: Eine anwendungsorientierte Einführung [Data analysis with Mplus: A practical introduction]. Wiesbaden, Germany: VS Verlag für Sozialwissenschaften. https://doi.org/10.1007/978-3-531-92042-9

Huber, C., Husfeldt, V., Lehmann, L., \& Quesel, C. (2008). Projektteil D2: Die Qualität von Maturaarbeiten in der Schweiz [Project part D2: The Quality of Matura Work in Switzerland.]. In F. Eberle, K. Gehrer, B. Jaggi, M. Kottnau, M. Oepke, C. Pflüger, C. Huber, V. Husfeldt, L. Lehmann, \& C. Quesel (Eds.), Evaluation der Maturitätsreform 1995 (EVAMAR). Schlussbericht zur Phase II (pp. 277-352). Bern, Switzerland: EDI, SBF. Retrieved from http://edudoc.ch/record/29677/files/Web_Evamar-Komplett.pdf

Huber, C., Lehmann, L., \& Husfeldt, V. (2011). Unterschiedliche Rahmenbedingungen bei der Realisierung von Maturaarbeiten [Differing framework conditions for the realisation of Matura theses]. Revue suisse des sciences de l'éducation, 33(3), 443-460. Retrieved from https://www.pedocs.de/volltexte/2015/10122/pdf/SZBW_2011_3_Huber_ua_Unterschiedliche_Rahmenbedingungen.pdf

Järvelä, S. (2011). How does help seeking help? - New prospects in a variety of contexts. Learning and Instruction, 21, 297-299. https://doi.org/10.1016/j.learninstruc.2010.07.006

Karabenick, S. A. (1998). Strategic help-seeking: Implications for learning and teaching. Mahwah, NJ: Erlbaum.

Karabenick, S. A. (2003). Seeking help in large college classes: A person-centered approach. Contemporary Educational Psychology, 28, 37-58. https://doi.org/10.1016/S0361-476X(02)000127

Karabenick, S. A., \& Berger, J.-L. (2013). Help seeking as a self-regulated learning strategy. In H. Bembenutty, T. J. Cleary, \& A. Kitsantas (Eds.), Applications of self-regulated learning across diverse disciplines: A tribute to Barry J. Zimmerman (pp. 237-261). Charlotte, NC: Information Age Publishing.

Karabenick, S. A., \& Gonida, E. N. (2018). Academic help seeking as a self-regulated learning strategy: Current issues, future directions. In D. H. Schunk \& J. A. Greene (Eds.), Handbook of SelfRegulation of Learning and Performance (pp. 421-433). New York, NY: Routlege.

Karabenick, S. A., \& Knapp, J. R. (1988). Help seeking and the need for academic assistance. Journal of Educational Psychology, 80(3), 406-408. https://doi.org/10.1037/0022-0663.80.3.406 
Karabenick, S. A., \& Knapp, J. R. (1991). Relationship of academic help seeking to the use of learning strategies and other instrumental achievement behavior in college students. Journal of Educational Psychology, 83(2), 221-230. https://doi.org/10.1037/0022-0663.83.2.221

Karabenick, S. A., \& Newman, R. S. (2006). Help seeking in academic settings: Goals, Groups and Contexts. Mahwah, N.J.: Lawrence Erlbaum Associates.

Karabenick, S. A., \& Newman, R. S. (2010). Seeking help as an adaptive response to learning difficulties: Person, situation, and developmental influences. In S. Järvela (Ed.), Social and emotional aspects of learning (pp. 244-250). Kidlington, Oxford, UK: Elsevier. https://doi.org/10.1016/B978-0-08-044894-7.00610-2

Magnusson, D. (1998). The logic and implications of a person-oriented approach. In R. B. Cairns, L. R. Bergman, \& J. Kagan (Eds.), Methods and models for studying the individual: Essays in honor of Marian Radke-Yarrow (pp. 33-64). Thousand Oaks, CA: Sage.

Makara, K. A., \& Karabenick, S. A. (2013). Characterizing sources of academic help in the age of expanding educational technology: A new conceptual framework. In S. A. Karabenick \& M. Puustinen (Eds.), Advances in help-seeking research and applications: The role of emerging technologies (pp. 37-72). Charlotte, NC: Information Age Publishing.

Martens, J. (2003). Statistische Datenanalyse mit SPSS für Windows [Statistical data analysis with SPSS for Windows]. Munich, Germany: Oldenbourg Wissenschaftsverlag. https://doi.org/10.1515/9783486815085

McCardle, L., Webster, E. A., Haffey, A., \& Hadwin, A. F. (2017). Examining students' self-set goals for self-regulated learning: Goal properties and patterns. Studies in Higher Education, 42(11), 2153-2169. https://doi.org/10.1080/03075079.2015.1135117

Muthén, B. O., \& Asparouhov, T. (2011, 27. July). LTA in Mplus: Transition probabilities influenced by covariates. Mplus Web Notes: No. 13. Retrieved from http://www.statmodel.com/examples/LTAwebnote.pdf

Muthén, L. K., \& Muthén, B. O. (1998-2017). Mplus user's guide (8th ed.). Los Angeles, CA: Muthén \& Muthén. Retrieved from https:/www.statmodel.com/download/usersguide/MplusUserGuideVer_8.pdf

Nadler, A. (1998). Relationship, esteem, and achievement perspectives on autonomous and dependent help seeking. In S. Karabenick (Ed.), Strategic help seeking: Implications for learning and teaching (pp. 61-93). Mahwah, New Jersey: Erlbaum.

Nagin, D. S. (2005). Group-based modeling of development. Cambridge, MA: Harvard Press. https://doi.org/10.4159/9780674041318

Nelson-Le Gall, S. (1981). Help-seeking: An understudied problem-solving skill in children. Developmental Review, 1(224-246). https://doi.org/10.1016/0273-2297(81)90019-8

Nelson-Le Gall, S. (1985). Help-seeking behavior in learning. Review of Research in Education, 12, 55-90. https://doi.org/10.3102/0091732X012001055

Nelson Le Gall, S., Gumerman, R. A., \& Scott-Jones, D. (1983). Instrumental help-seeking and everyday problem-solving: A developmental perspective. In B. M. De-Paulo, A. Nadler, \& J. D. Fisher (Eds.), New directions in helping (pp. 265-281). New York, NY: Academic Press.

Newman, R. S. (2000). Social influences on the development of children's adaptive help-seeking: The role of parents, teachers, and peers. Developmental Review, 20, 350-404. https://doi.org/10.1006/drev.1999.0502 
Nylund, K. L. (2007). Latent transition analysis: Modeling extensions and an application to peer victimization. Retrieved from http://www.statmodel.com/download/Nylund\%20dissertation\%20Updated1.pdf

Pintrich, P. R., \& Zusho, A. (2002). The development of academic self-regulation: The role of cognitive and motivational factors. In A. Wigfield \& J. S. Eccles (Eds.), Development of achievement motivation (pp. 249-284). San Diego, CA: Academic Press. https://doi.org/10.1016/B978012750053-9/50012-7

Rickwood, D. J. (1995). The effectiveness of seeking help for coping with personal problems in late adolescence. Journal of Youth and Adolescence, 24, 685-703. https://doi.org/10.1007/BF01536951

Ritschl, V., Weigl, R., \& Stamm, T. (2016). Wissenschaftliches Arbeiten und Schreiben. Verstehen, Anwenden, Nutzen für die Praxis [Academic work and writing. Comprehension, application and benefit for practice]. Berlin, Germany: Springer. https://doi.org/10.1007/978-3-662-49908-5

Robins, R. W., John, O. P., \& Caspi, A. (1998). The typological approach to studying personality. In R. B. Cairns, L. R. Bergman, \& J. Kagan (Eds.), Methods and models for studying the individual: Essays in honor of Marian Radke-Yarrow (pp. 135-160). Thousand Oaks, CA: Sage.

Rost, J. (2006). Latent class analysis. In F. Petermann \& M. Eid (Eds.), Handbuch der Psychologischen Diagnostik [Manual of psychological diagnostics]. Göttingen, Germany: Hogrefe Verlag.

Ryan, A. M., Patrick, H., \& Shim, S.-O. (2005). Differential profiles of students identified by their teacher as having avoidant, appropriate, or dependent help-seeking tendencies in the classroom. Journal of Educational Psychology, 97(2), 275-285. https://doi.org/10.1037/00220663.97.2.275

Ryan, A. M., \& Pintrich, P. R. (1997). "Should I ask for help?” The role of motivation and attitudes in adolescents' help seeking in math class. Journal of Educational Psychology, 89, 329-341. https://doi.org/10.1037/0022-0663.89.2.329

Ryan, A. M., Pintrich, P. R., \& Midgley, C. (2001). Avoiding seeking help in the classroom: Who and why? Educational Psychology Review, 13(2), 93-114. https://doi.org/10.1023/A:1009013420053

Ryan, A. M., \& Shim, S. S. (2012). Changes in help seeking from peers during early adolescence: Associations with changes in achievement and perceptions of teachers. Journal of Educational Psychology, 104(4), 1122-1134. https://doi.org/10.1037/a0027696

Ryan, A. M., \& Shin, H. (2011). Help-seeking tendencies during early adolescence: An examination of motivational correlates and consequences for achievement. Learning and Instruction, 21, 247-256. https://doi.org/10.1016/j.learninstruc.2010.07.003

Scardamalia, M., \& Bereiter, C. (1992). Text-based and knowledge-based questioning by children. Cognition and Instruction, 9(3), 177-199. https://doi.org/10.1207/s1532690xci0903_1

Schenke, K., Lam, A. C., Conley, A. M., \& Karabenick, S. A. (2015). Adolescents' help seeking in mathematics classrooms: Relations between achievement and perceived classroom environmental influences over one school year. Contemporary Educational Psychology, 41, 133-146. https://doi.org/10.1016/j.cedpsych.2015.01.003

Schworm, S. (2018). Lernen in computerbasierten Lernumgebungen: Instruktionale Unterstützungsmöglichkeiten [Learning in computer-based learning environments: Instructional support possibilities]. In M. Heilemann, H. Stöger, \& A. Ziegler (Eds.), Lernen im Internet (pp. 93112). Berlin, Germany: Lit Verlag. 
Schworm, S., \& Fischer, F. (2006). Academic help seeking. In H. Mandl \& H. F. Friedrich (Eds.), Handbuch Lernstrategien (pp. 282-239). Göttingen, Germany: Hogrefe.

Sheskin, D. J. (2011). Handbook of parametric and nonparametric statistical procedures. Boca Raton, FL: Chapman \& Hall/CRC Press.

Specht, J., Luhmann, M., \& Geiser, C. (2014). On the consistency of personality types across adulthood: Latent profile analyses in two large-scale panel studies. Journal of Personality and Social Psychology, 107, 540-556. https://doi.org/10.1037/a0036863

Stroebe, W., Hewstone, M., Codol, J.-P., \& Stephenson, G. M. (2013). Sozialpsychologie: Eine Einführung. [Social psychology: An introduction]. Heidelberg, Germany: Springer Verlag.

Swiss Federal Council, \& EDK. (1995). Verordnung des Bundesrates/Reglement der EDK über die Anerkennung von gymnasialen Maturitätsausweisen (MAR) vom 16. Januar/15. Februar 1995 [Ordinance of the Federal Council/Regulation of the EDK on the Recognition of Matura Certificates (MAR) of 16 January/15 February 1995]. Bern, Switzerland: Schweizerischer Bundesrat/EDK. Retrieved from https://edudoc.educa.ch/static/web/aktuell/medienmitt/vo_mar_1995_d.pdf

Tinsley, H. E. A., de St. Aubin, T., \& Brown, M. (1982). College students' help-seeking preferences. Journal of Counselling Psychology, 29, 523-533. https://doi.org/10.1037/0022-0167.29.5.523

Ulmi, M., Bürki, G., Verhein, A., \& Marti, M. (2017). Textdiagnose und Schreibberatung. Fach- und Qualifizierungsarbeiten begleiten [Text diagnosis and writing advice: Accompanying specialized and qualification work] (2nd ed.). Berlin, Germany: Barbara Budrich.

Wolters, C. A. (2003). Regulation of motivation: Evaluating an underemphasized aspect of self-regulated learning. Educational Psychologist, 38(4), 189-205. https://doi.org/10.1207/S15326985EP3804_1

Wolters, C. A., Pintrich, P. R., \& Karabenick, S. A. (2003). Assessing academic self-regulated learning. Paper presented at Conference on Indicators of Positive Development: Definitions, Measures, and Prospective Validity, Washington DC. Retrieved from https:/www.researchgate.net/profile/Stuart_Karabenick/publication/225229608_Assessing_Academic_SelfRegulated_Learning/links/5416daec0cf2bb7347db788a/Assessing-Academic-Self-RegulatedLearning.pdf

Zimmerman, B. J. (2002). Becoming a self-regulated learner: An overview. Theory Into Practice, 4l(2). https://doi.org/10.1207/s15430421tip4102_2

Zimmerman, B. J., \& Moylan, A. R. (2009). Where metacognition and motivation intersect. In D. J. Hacker, J. Dunlosky, \& A. C. Graesser (Eds.), Handbook of metacognition in education. New York, NY: Routledge. 